UNIVERSIDADE DE SÃO PAULO
HOSPITAL DE REABILITAÇÃO DE ANOMALIAS CRANIOFACIAS

RENAN VICTOR FIRMINO MORAIS

Crescimento facial em indivíduos com fissura de lábio e palato unilateral completa (FLPUC): acompanhamento cefalométrico longitudinal 
RENAN VICTOR FIRMINO MORAIS

\section{Crescimento facial em indivíduos com fissura de lábio e palato unilateral completa (FLPUC): acompanhamento cefalométrico longitudinal}

Dissertação apresentada ao Hospital de Reabilitação de Anomalias Craniofaciais da Universidade de São para obtenção do título de Mestre em Ciências da Reabilitação, na área de concentração Fissuras Orofaciais e Anomalias Relacionadas.

Orientadora: Dra. Terumi Okada Ozawa 


\section{Morais, Renan Victor Firmino Morais}

Crescimento facial em indivíduos com fissura de lábio e palato unilateral completa (FLPUC): acompanhamento cefalométrico longitudinal / Renan Victor Firmino Morais. - Bauru, 2020.

71 p.; il.; $31 \mathrm{~cm}$.

Dissertação (Mestrado - Fissuras Orofaciais e Anomalias Relacionadas) - Hospital de Reabilitação de Anomalias Craniofaciais, Universidade de São Paulo.

Orientadora: Dra. Terumi Okada Ozawa

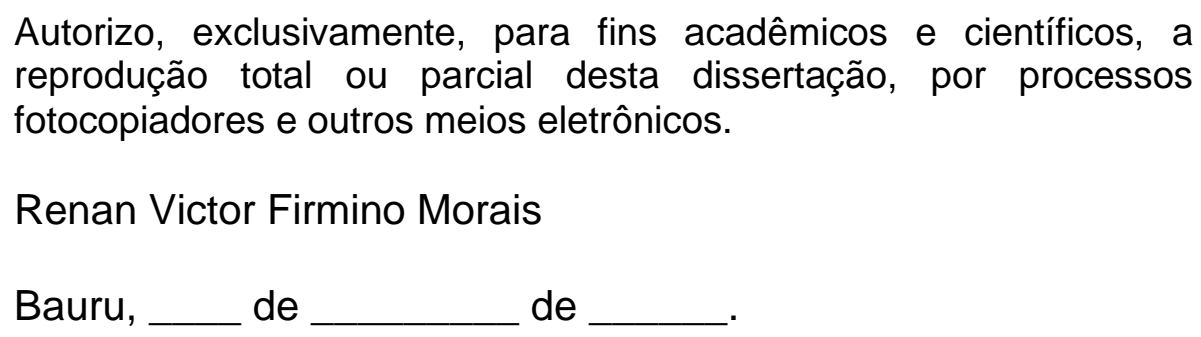

Bauru, de de

CAAE: 95634118.4 .0000 .5441

Data: 30/08/2018 




\title{
DEDICATÓRIA
}

\begin{abstract}
A Deus,
por guiar e proteger meus passos

nos momentos de grandes desafios.
\end{abstract}

Minha eterna gratidão em forma de oração. 


\section{AGRADECIMENTOS}

A CAPES, pela contribuição e oportunidades de crescer durante o curso de Pós-Graduação.

À minha mãe Ivone, minha gratidão.

Ao meu irmão Victor, pelo companheirismo.

Ao meu companheiro Felipe, pelo incondicional e infinito apoio recebido.

Aos meus colegas de mestrado, pelas experiências compartilhadas.

Às secretarias da pós-graduação, em especial a Ana Regina, Zezé, Lavínia e Luci, pela constante ajuda em todos os momentos que necessitei.

A todos os funcionários e colaboradores do HRAC, sem os quais este trabalho não teria concluído.

Aos pacientes do HRAC, razão deste trabalho.

À minha orientadora.

A todos que contribuíram de alguma forma.

Minha eterna gratidão! 
"Cada sonho que você deixa para trás, é um pedaço do seu futuro que deixa de existir."

Steve Jobs 


\section{RESUMO}

Objetivos: avaliar longitudinalmente por meio de análise cefalométrica, o crescimento craniofacial em 349 indivíduos com FLPUC, e a influência das técnicas de queiloplastia (Spina vs. Millard) e palatoplastia em um tempo (Furlow vs. Von Langenbeck), a idade no momento da cirurgia de palatoplastia (9 a 12 meses vs. 15 a 18 meses) e a influência dos quatro cirurgiões que realizaram a cirurgia sobre o crescimento craniofacial, e o percentual de casos com prognostico ortodônticocirúrgico na amostra total. Metodologia: foram avaliadas 698 telerradiografias laterais no "software Dolphin Imaging 11.8" com medidas angulares/sagitais de 349 indivíduos com FLPUC registrados no Hospital de Reabilitação de Anomalias Craniofaciais nas fases T1 (dentadura mista) e T2 (dentadura permanente). Resultados e Conclusão: observou-se que em $\mathrm{T} 1$ o número de casos com $\mathrm{ANB}<0$ eram muito maiores que em T2. Após manejo ortodôntico-ortopédico, em T2, o ANB $>0$ aumentou pelo posicionamento mais anterior da maxila e devido a rotação horária da mandíbula; o SNA $>80^{\circ}$ aumentou consideravelmente, enquanto o SNB $>80^{\circ}$ reduziu consideravelmente, com tendência de rotação mandíbular no sentido horário, para baixo e para trás. Da amostra total $(n=349$ ), observou-se na fase T2 (após acompanhamento ortodôntico-ortopédico + EOA), um percentual de 9,73\% com ângulo ANB de (-7ํ- a - $\left.1^{\circ}\right)$, com provável prognóstico ortodôntico-cirúrgico e $70 \%$ dos casos com ANB $>2^{\circ}$, compatível com os indivíduos normais sem fissura. A técnica de Queiloplastia (Millard ou Spina) não influenciaram nem na posição sagital da maxila (SNA), da mandíbula (SNB) e na relação maxilomandibular (ANB) na fase T1 eT2. A técnica de palatoplastia (VL ou Furlow) não influenciaram na posição maxilar (SNA) e mandibular (SNB), nas fases T1 e T2. No entanto, a técnica de VL influenciou mais negativamente no ANB do que a técnica de $F$, na fase T1. Na fase T2, o ANB foi similar nas técnicas VL e F. O comportamento sagital da maxila (SNA), mandíbula (SNB) não apresentaram diferença estatística entre os subgrupos operados pela técnica de: (SF); (S-VL); (M-F); (VL), tanto em T1 como em T2. Somente a técnica M-VL $(-2,58)$ mostrou-se menos favorável que M-F $(-0,58)$ em T1, enquanto em T2, após o tratamento ortodôntico/ortopédico, todos os grupos ( $M-V L$; M-F, S-VL e S-F) tiveram a relação sagital corrigida e apresentaram a média dos ângulos $A N B ~>+3^{\circ}$ (próximo de um indivíduo sem FLP) e sem diferença estatística. O fechamento do palato em 
um único estágio, em idade precoce (9-12 meses) e tardio (15-18 meses) não apresentou diferença estatística no comportamento do SNA e SNB operados por diferentes técnicas (SF; SVL; MF; MVL), nas fases T1 e T2. Apenas na fase T1 o ANB apresentou uma discrepância mais negativa no grupo operado mais precocemente $(A N B=-2,2)$ do que o grupo operado mais tardiamente $(A N B=-1,3)$. Valor de $p=0,03^{*}$. $\mathrm{Na}$ fase T2 essa diferença do ANB entre o grupo operado precoce e tardiamente foi corrigida após o manejo ortodôntico e ortopédico. A média dos dois grupos passaram de ANB negativo para um ANB acima de 3,5, compatível à de indivíduos sem fissura. Não houve diferença estatística na relação sagital da maxila (SNA) entre os quatro cirurgiões, nas fases T1 e T2. Houve diferença estatisticamente significante na relação maxilomandibular (ANB) na fase T1 entre os cirurgiões 2 e 3 (mais favorável). Em T2, todos os quatro cirurgiões apresentaram resultados satisfatórios, com ANB positivos e próximos dos valores médios de indivíduos sem fissura.

Palavras-chave: Cefalometria. Crescimento e desenvolvimento. Fissura labiopalatina. 


\section{ABSTRACT \\ Facial growth in individuals with cleft lip and complete unilateral palate (FLPUC): longitudinal cephalometric follow-up}

Objectives: to evaluate longitudinally by cephalometric analysis, craniofacial growth in 349 individuals with CUCLP, and the influence of cheiloplasty (Spina vs. Millard) and palatoplasty techniques at one time (Furlow vs. Von Langenbeck). palatoplasty surgery (9 to 12 months vs. 15 to 18 months). It was also verified the influence of the 4 surgeons who performed the surgery on craniofacial growth, and the percentage of cases with orthodontic-surgical prognosis in the total sample. Methodology: 698 lateral cephalograms were evaluated in the "Dolphin Imaging 11.8" software with angular / sagittal measurements of 349 individuals with FLPUC registered at the Craniofacial Anomalies Rehabilitation Hospital in phases T1 (mixed dentures between 6 and 10 years old) and T2 (dentures). from 14 years old). Results and Conclusion: based on the longitudinal cephalometric results it was observed that in T1 the number of cases with ANB <0 was much higher than in T2. After orthodontic-orthopedic management, in T2, the ANB >0 increased due to the more anterior position of the maxilla and due to the clockwise rotation of the mandible; the SNA $>80^{\circ}$ increased considerably, while the SNB $>80^{\circ}$ decreased considerably, with a tendency for mandibular rotation in a clockwise direction, downwards and backwards. From the total sample $(n=349)$, it was observed in phase T2 (after orthodontic-orthopedic follow-up + OAE), a percentage of $9.73 \%$ with probable surgical-orthodontic prognosis and $70 \%$ of cases with ANB $>2 \%$, compatible with normal individuals without cleft. The cheiloplasty technique (Millard or Spina) did not influence either the sagittal position of the maxilla (SNA), the mandible (SNB) or the maxillomandibular relationship (ANB) in the T1 and T2 phases. The palatoplasty technique (VL or Furlow) did not influence the maxillary (SNA) and mandibular (SNB) position, in phases $\mathrm{T} 1$ and $\mathrm{T} 2$. However, the $\mathrm{VL}$ technique influenced the ANB more negatively than the $\mathrm{F}$ technique, in the T1 phase. In phase T2, ANB was similar in the VL and F techniques. The sagittal behavior of the maxilla (SNA), mandible (SNB) showed no statistical difference between the subgroups operated by the technique of: (S-F); (S-VL); (M-F); (VL), both in T1 and T2. Only the M-VL technique (-2.58) was less favorable than MF $(-0.58)$ in $T 1$, while in T2, after orthodontic / orthopedic treatment, all groups (M-VL; MF, S -VL and SF) had the 
sagittal relationship corrected and presented the mean ANB angles $>+3^{\circ}$ (close to an individual without CLP) and without statistical difference. The closure of the palate in a single stage, at an early age (9-12 $\mathrm{m})$ and late (15-18 m), did not show statistical difference in the behavior of the SNA and SNB operated by different techniques (SF; SVL; MF; MVL), in phases T1 and T2. Only in phase T1 (mixed dentition), the ANB presented a more negative discrepancy in the group operated earlier ( $A N B=-2.2)$ than the group operated later $(A N B=-1.3)$. $P$-value $=0,03^{*}$. In phase $T 2$, this difference in ANB between the early and late operated groups was corrected after orthodontic and orthopedic management. The average of the 2 groups went from a negative ANB to an ANB above 3.5, compatible with that of individuals without cleft. There was no statistical difference in the sagittal maxillary position (SNA) between the 4 surgeons, in phases $\mathrm{T} 1$ and $\mathrm{T} 2$. There was a statistically significant difference in the maxillomandibular relationship (ANB) in phase T1 between surgeons 2 and 3 (more favorable). In T2, all 4 surgeons presented satisfactory results, with positive ANB and close to the average values of individuals without cleft.

Keywords: Cephalometric. Growth and development. Unilateral cleft lip and palate. 


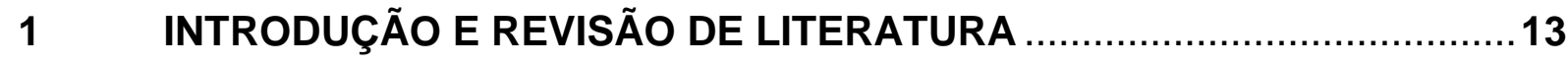

2 OBJETIVOS

2.1 OBJETIVOS ESPECÍFICOS …..........................................................23

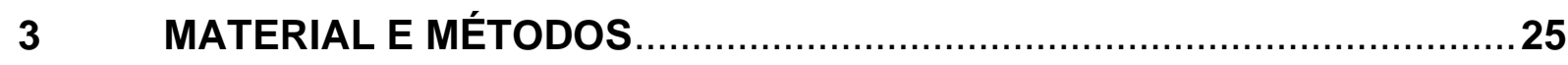

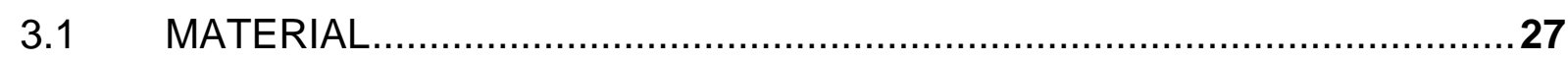

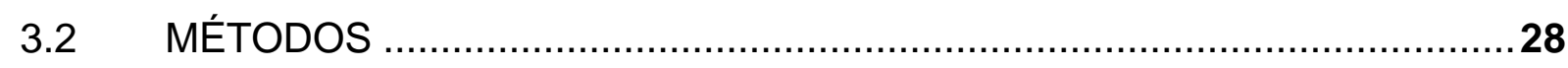

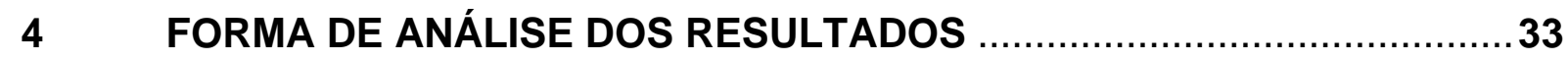

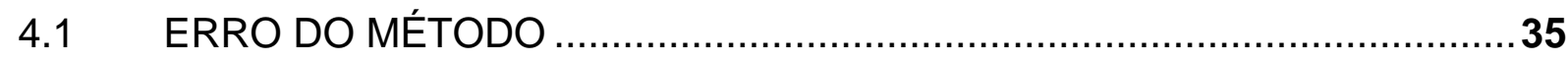

4.2 ANÁLISE ESTATÍSTICA ENTRE OS GRUPOS ............................................

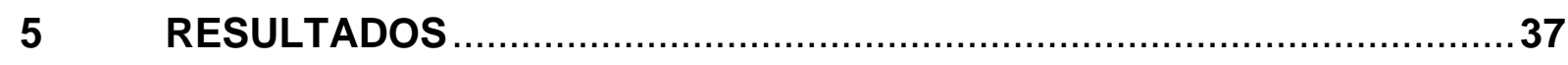

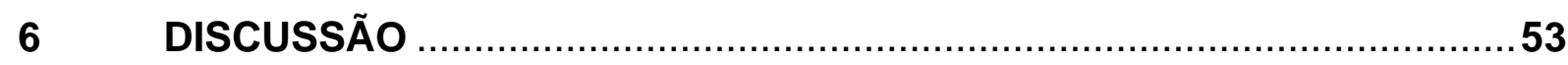

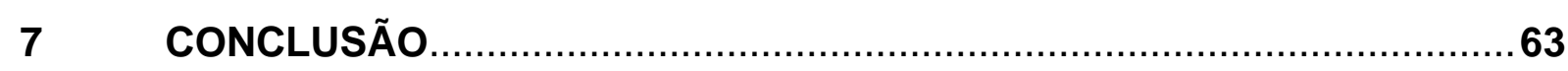

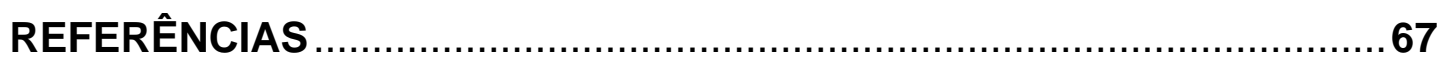




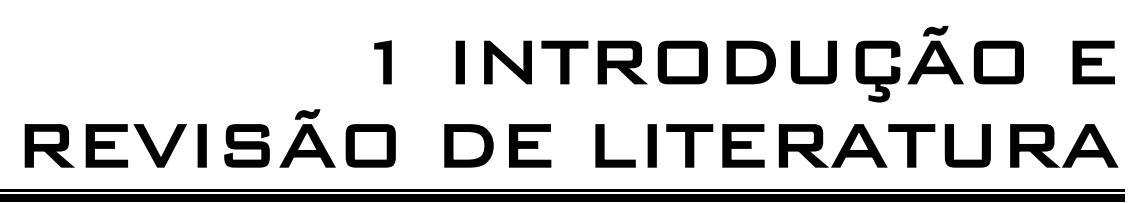





\section{INTRODUÇÃO E REVISÃO DE LITERATURA}

A fissura labiopalatina é frequente na população (MURRAY, 2002), sendo uma malformação craniofacial que ocorre na vida intrauterina no final do período embrionário e início do período fetal, durante a formação da face (MARQUES; LOPES; KHOUTY, 1997). De etiologia multifatorial, engloba fatores genéticos e ambientais e, no Brasil, a incidência é em torno de 1: 650 nascimentos (FREITAS et al., 2012a). A fissura de lábio e palato unilateral completa (FLPUC), a qual tem o comprometimento labial, do rebordo alveolar e palato, é a mais frequente entre os tipos de fissuras não sindrômicas (CYMROT et al., 2010). Em sentido embriológico, seria a ausência de fusão entre o palato primário, o processo maxilar e o palato secundário de um dos lados (TRINDADE; SILVA FILHO, 2007).

O tratamento cirúrgico reabilitador em indivíduos com fissura de lábio e palato começa com a queiloplastia e palatoplastia, as quais são responsáveis por reestruturar a forma, função e estética do lábio e palato respectivamente. A influência da idade em que será realizada a cirurgia, ou seja, o momento ideal para realização dos procedimentos cirúrgicos e as técnicas de queiloplastia e palatoplastia podem alterar o tratamento em indivíduos com FLPUC (FUDALEJ et al., 2011; LIAO; COLE; MARS, 2006 apud HAQUE; ALAM; KHAMIS, 2017). Na técnica de Spina, os retalhos são triangulares e, na técnica modificada, procedimentos são realizados para melhorar o aspecto do vermelhão do lábio, além da marcação e orientação dos retalhos da plástica em Z (ANGER, 2005; MIACHON; LEME, 2014). A técnica de Millard para o fechamento do lábio por sua vez, consiste em avançar o retalho da vertente lateral do lado com fissura, rotar a vertente medial do lado sem fissura, originando uma cicatriz vertical em forma de Z (TRINDADE; SILVA FILHO, 2007). As técnicas de Furlow e Von Langenbeck são utilizadas em diferentes centros de reabilitação para a cirurgia de palatoplastia e devem reestabelecer a forma e função do palato. A técnica de Furlow consiste em uma dupla zetaplastia realizada no palato posterior (uma na mucosa oral e outra, inversa, na mucosa nasal) associada ao reposicionamento dos músculos levantadores do palato, seguida do fechamento do palato duro com o retalho vomeriano em uma ou duas camadas (FURLOW, 1978; FURLOW, 1986). Já a técnica de Von Langenbeck é realizada a partir da incisão na margem de ambos os lados da fissura, seguida do descolamento dos retalhos 
mucoperiosteais, enquanto os músculos são separados por aponeurose palatina, podendo ter incisões liberadoras (da região retromolar até caninos) com objetivo de permitir a aproximação dos retalhos mucoperiosteais (com veloplastia intravelar) (TRINDADE; SILVA FILHO, 2007).

Entretanto, durante 0 crescimento craniofacial, as cirurgias primárias demonstraram uma influência negativa sobre a maxila e o complexo maxilomandibular (OZAWA, 2001; GARIB et al., 2010). Ainda é difícil isolar estes fatores tornando-se limitada a hipótese de que o comprometimento do crescimento seja o único e exclusivo fator determinante neste processo (BICHARA et al., 2015). Os arcos maxilares em pacientes com FLPUC também mostraram mudanças após as cirurgias primárias, sendo que, o lábio superior mostrou maior influência na região anterior do arco e o reparo do palato inibiu o crescimento transversal (SAKODA et al., 2017). O terço médio da face apresenta-se retruído, indicando um crescimento deficiente (SEMB, 1991), enquanto as dimensões diminuídas nos sentidos ântero-posterior, transversal e sagital, resultaram na convexidade facial e retrognatismo maxilar (CAVASSAN; SILVA FILHO, 2007; MOREIRA et al., 2014).

Em contrapartida, indivíduos que não foram submetidos à cirurgia de lábio e palato na infância tiveram um melhor desempenho de crescimento maxilar, mas, ainda é um desafio avaliar isoladamente estes fatores que podem alterar 0 desenvolvimento maxilar (MARS; HOUSTON, 1990; CAPELOZZA FILHO; NORMANDO; SILVA FILHO, 1996). Porém, a posição dos incisivos superiores e 0 crescimento mandibular não mostraram alterações quando o palato foi reparado (LIAO; MARS, 2005).

Um dos exames complementares capazes de dimensionar as estruturas ósseas e a gravidade da discrepância maxilomandibular é a radiografia. Broadbent (1931) e Hofrath (1931) apresentaram uma nova técnica radiográfica com o uso do cefalostato, a telerradiografia cefalométrica. Devido à quantificação dos dados e a padronização das técnicas radiográficas, o uso da telerradiografia expandiu-se na área da pesquisa por permitir comparações em idades distintas e entre diferentes indivíduos de uma mesma amostra. Atualmente, softwares e programas computadorizados são capazes de realizar traçados cefalométricos, incluindo as mensurações das grandezas angulares e lineares (VASCONCELOS, 2000). 
O crescimento e desenvolvimento desequilibrado das estruturas craniofaciais, observados a partir de análises cefalométricas, pode também alterar o perfil facial e acarretar alterações esqueléticas (CAPELOZZA FILHO; NORMANDO; SILVA FILHO, 1996). As dimensões faciais do terço médio e inferior da face são menores em todas as direções de crescimento em crianças que não passaram por tratamento ortodôntico, com restrição da largura e comprimento do arco maxilar. Apresentou-se um padrão dentário e esquelético de Classe III (GOPINATH et al. 2017).

Indivíduos com fissura de lábio e palato completa operados mostram uma deficiência sagital maxilar grave, acompanhada de redução dos ângulos SNA e SN.ANS (FREITAS et al., 2012b). No centro de reabilitação de Oslo, Noruega, um estudo longitudinal realizado demonstrou um ângulo SNA reduzido em idades precoces (79,6 ${ }^{\circ}$ aos 5 anos de idade). Porém, em fase de crescimento, a deficiência maxilar avaliada apresentou uma redução progressiva, levando a um valor médio de SNA de $74,2^{\circ}$ aos 18 anos de idade (SEMB, 1991).

Figura 1 - Valores de SNA em indivíduos com FLPUC, FLPBC e indivíduos sem fissura

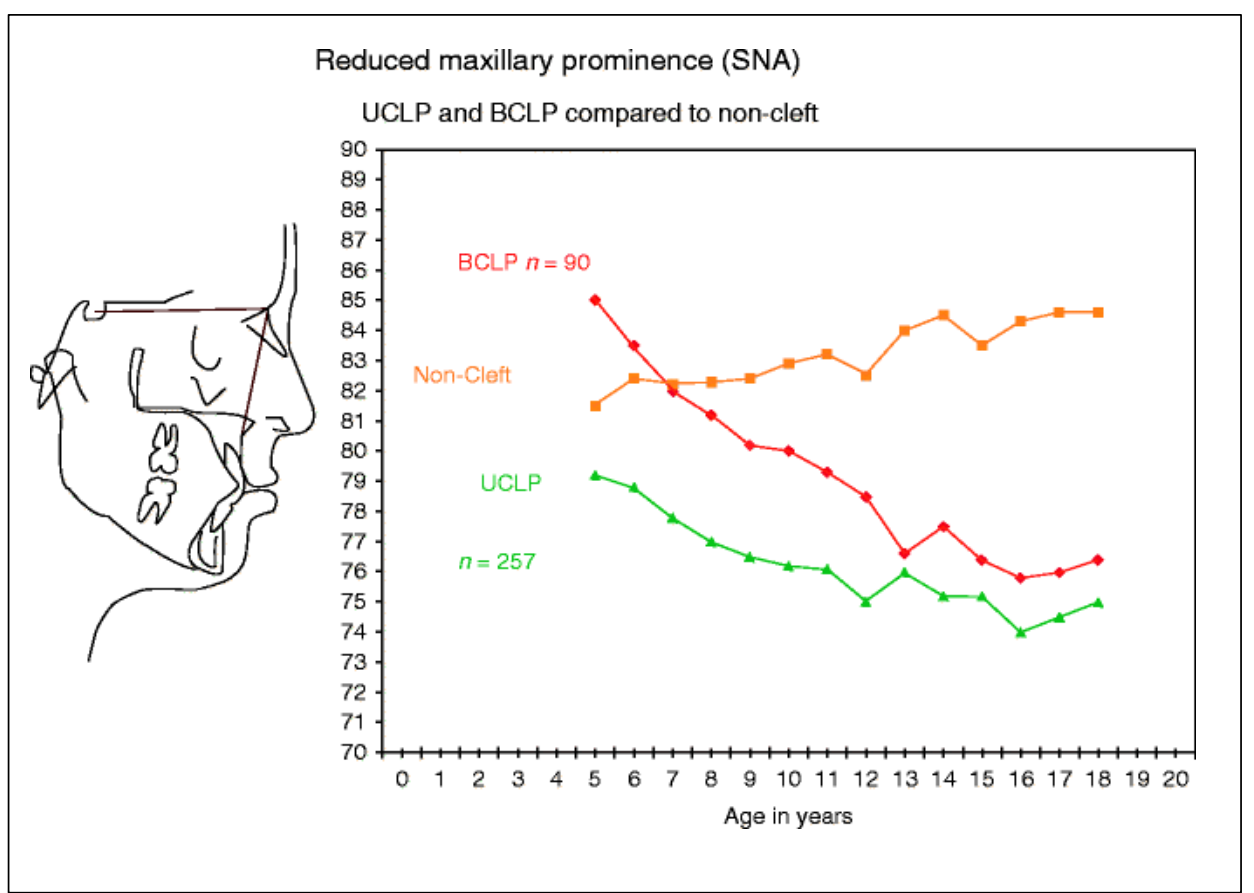

Fonte: Semb (1991). 
As técnicas cirúrgicas para reparo do palato podem apresentar diferentes desempenhos para fala e crescimento craniofacial em indivíduos com fissura (LEOW; LO, 2008). É sugerido que, em futuros protocolos de tratamento, não somente seja avaliada a idade no momento da cirurgia, mas também, uma minimização do tecido cicatricial com a finalidade de reduzir os distúrbios associados ao crescimento ao longo da vida (KAPPEN et al., 2017). Alguns protocolos de reabilitação nas cirurgias primárias foram verificados, tanto a idade no momento da cirurgia, quanto 0 fechamento do palato em fase única ou duas etapas, mas não foram encontradas diferenças estatísticas entre os protocolos abaixo até os 5.1 anos de idade (HELIÖVAARA et al., 2017).

Figura 2 - Protocolos das cirurgias primárias

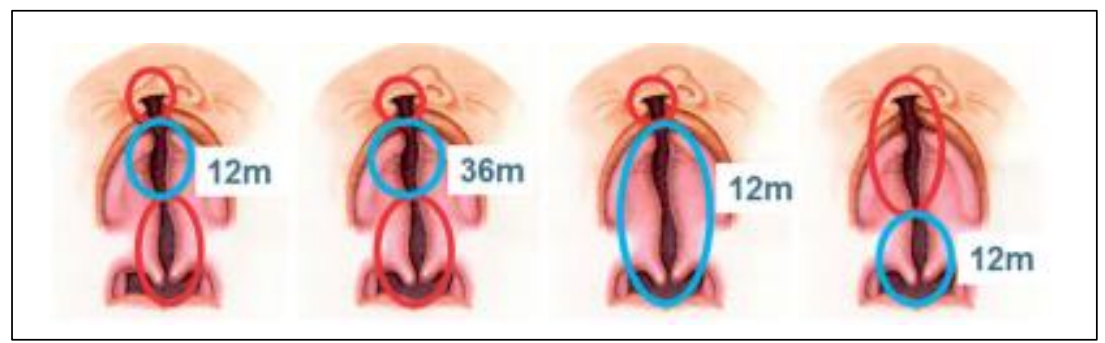

Fonte: Heliövaara et al. (2017).

Estudos realizados no Hospital de Reabilitação de Anomalias Craniofaciais (HRAC-USP) na cidade de Bauru, avaliaram resultados de crescimento e fala em indivíduos com FLPUC na infância (WILLIAMS et al., 2011). Os indivíduos participantes foram randomizados pelo (1) reparo do lábio pela técnica de Spina ou Millard; (2) reparo do palato pela técnica de Furlow ou Von Langenback; e (3) a idade que foi realizado o reparo do palato em 9 a 12 meses ou 15 a 18 meses. Todas as cirurgias foram realizadas por quatro cirurgiões. Relatou-se que a função velofaríngea teve melhor desempenho quando realizada a técnica de Furlow, mas apresentou maior ocorrência de fístulas. Com os anos de tratamento para reabilitação, novas documentações, como as telerradiografias laterais, compuseram uma amostra significativa para agregar resultados longitudinais destes indivíduos na adolescência e fase adulta.

Por todos os fatores apresentados, o presente estudo teve por finalidade avaliar o crescimento craniofacial de indivíduos com FLPUC em um estudo 
prospectivo longitudinal oobservando as alterações sagitais da maxila e mandíbula dos indivíduos com FLPUC nas diferentes fases do crescimento desde a dentadura decídua/mista precoce à dentadura permanente. 

2 口BJETIVDS 



\section{OBJETIVOS}

Avaliar longitudinalmente o crescimento craniofacial sagital em indivíduos com FLPUC, por meio da análise cefalométrica.

\subsection{OBJETIVOS ESPECÍFICOS}

* Avaliar longitudinalmente o crescimento craniofacial sagital em indivíduos com FLPUC, e a relação com as técnicas de queiloplastia (Spina vs. Millard) e palatoplastia em um tempo (Furlow vs. Von Langenbeck) por meio de análise cefalométrica em dois diferentes estágios: T1 (dentadura decídua/mista entre 6 e 10 anos), e T2 (dentadura permanente a partir dos 14 anos de idade).

* Avaliar a relação entre o crescimento craniofacial sagital e as técnicas utilizadas na queiloplastia e palatoplastia: Spina (S) vs. Millard (M) e Von-Langembeck (VL) vs. Furlow (F).

* Avaliar a diferença entre o comportamento da maxila e a relação maxilomandibular entre os grupos operados pela técnica de: SpinaFurlow (S-F); Spina-Von Langenbeck (S-VL); Millard-Furlow (M-F); Millard-Von Langenbeck (VL).

* Avaliar a relação entre o crescimento craniofacial sagital e a idade do indivíduo FLPUC no momento da palatoplastia em um tempo entre 9 a 12 meses (precoce) e 15 a 18 meses(tardio).

* Verificar a influência dos quatro cirurgiões que realizaram as cirurgias de lábio e palato sobre o crescimento craniofacial sagital.

* Avaliar o porcentual de casos com prognostico ortodôntico-cirúrgico em relação às grandezas cefalométricas esqueléticas sagitais. 

3 MATERIAL E MÉTIDOS 



\section{MATERIAL E MÉTODOS}

\subsection{MATERIAL}

A amostra inicial foi composta por 466 indivíduos com FLPUC matriculados no HRAC-USP-Bauru no período de fevereiro de 1996 até dezembro de 2001, participantes de um projeto de pesquisa de caráter prospectivo e longitudinal visando comparar duas técnicas de queiloplastias (Spina-Millard) e duas técnicas de palatoplastias (Furlow-Von Langenbeck). O fechamento do lábio foi entre 3-6meses e o fechamento do palato num único estágio foi realizado em dois tempos distintos, entre 9-12 meses (precoce) e de 15-18 meses (tardio) por quatro cirurgiões experientes (WILLIAMS et al., 2011).

Este modelo de estudo 2x2x2 resultou em oito subgrupos, enquanto a variável cirurgião foi avaliado como covariável e comparado utilizando quatro formas de Análise Multivariada de Desacordo na avaliação final (Figura 3).

Figura 3 - Diagrama ilustrando os protocolos cirúrgicos do projeto prospectivo/randomizado e longitudinal do HRAC-USP

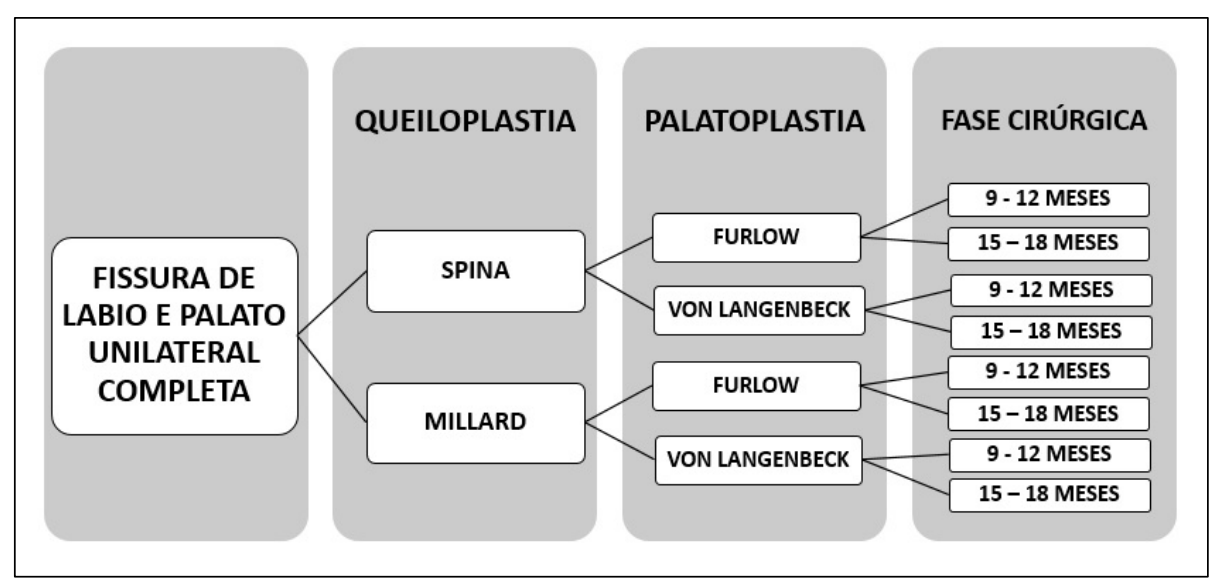

Nota: Amostra total inicial $\mathrm{n}=466$.

Fonte: Elaborada pelo autor.

Para o presente trabalho foram selecionados 349 pacientes, da amostra original de 466 pacientes, que apresentaram duas telerradiografias laterais em duas fases distintas: T1 - na dentadura decídua/mista precoce com idade média de 7 anos (6 a 10 anos) sem nenhum tratamento ortodôntico prévio nem enxerto ósseo alveolar (EOA) e T2- na dentadura permanente (a partir de 14 anos). Em T2 os pacientes já 
haviam sido submetidos ao tratamento ortodôntico/ortopédico (expansão maxilar, tração reversa da maxila, aparelhos ortodônticos fixos) e enxerto ósseo alveolar. Nos casos com prognostico ortodôntico-cirúrgico foram selecionadas as telerradiografias antes da cirurgia ortognática.

\subsection{MÉTODOS}

Foram avaliadas 698 telerradiografias laterais no software Dolphin Imaging 11.8 (Dolphin Imaging and Management Solutions, Chatsworth, Calif., EUA). com medidas angulares/sagitais de 349 indivíduos com FLPUC registrados no Hospital de Reabilitação de Anomalias Craniofaciais nas fases T1 (dentadura mista entre 6 e 10 anos de idade) e T2 (dentadura permanente, a partir dos 14 anos.

Inicialmente, as variáveis cefalométricas dento-esqueléticas e tegumentares compuseram os dados para a análise (STEINER, 1953; DOWNS, 1956; HOLDAWAY, 1956; RIEDEL, 1957; RICKETTS, 1968; TWEED, 1969; MCNAMARA, 1984). No entanto, no presente estudo, apenas as variáveis esqueléticas angulares/sagitais das bases apicais (SNA, SNB, ANB) foram analisadas e confrontando com as diferentes técnicas de queiloplastia e palatoplastia.

O traçado cefalométrico foi gerado após a marcação de alguns pontos extras tegumentares: dorso nasal, ponto mais inferior do lábio superior, ponto mais superior do lábio inferior, gnátio tegumentar (Gn'), ponto cervical; e alguns pontos extras esqueléticos: articular (Ar), sigmoide, processo coronoide, bordas vestibular e lingual dos rebordos alveolares dos incisivos superior e inferior. Após a marcação dos pontos cefalométricos, o software gerou valores lineares e angulares de variáveis préestabelecidas. A partir das variáveis estabelecidas, o traçado é gerado e acompanhado do valor das mensurações necessárias para análise estatística (Figura 4). 
Quadro 1 - Variáveis cefalométricas do perfil tegumentar, estrutura dentária, estrutura esquelética, linhas e planos de orientação utilizados na análise

\begin{tabular}{|c|c|c|c|c|c|}
\hline \multicolumn{3}{|r|}{ PERFIL TEGUMENTAR } & \multicolumn{3}{|r|}{ ESTRUTURA DENTÁRIA } \\
\hline 1 & Gl' & Glabela tegumentar & 12 & Is & Incisivo superior \\
\hline 2 & $\mathrm{~N}^{\prime}$ & Násio tegumentar & 13 & BIS & Borda incisal superior \\
\hline 3 & Prn & Pronasal & 14 & AIS & Ápice incisal superior \\
\hline 4 & $\mathrm{Cm}$ & Columela & 15 & li & Incisivo inferior \\
\hline 5 & Sn & Subnasal & 16 & BII & Borda incisal inferior \\
\hline 6 & $A^{\prime}$ & Ponto A tegumentar & 17 & All & Ápice incisal inferior \\
\hline 7 & Ls & Labial superior & 18 & MPMS & Mesial do primeiro molar superior \\
\hline 8 & $\mathrm{Li}$ & Labial inferior & 19 & OPMS & Oclusal do primeiro molar superior \\
\hline 9 & $B^{\prime}$ & Ponto B tegumentar & 20 & DPMS & Distal do primeiro molar superior \\
\hline 10 & Pog' & Pogônio tegumentar & 21 & MPMI & Mesial do primeiro molar inferior \\
\hline \multirow[t]{2}{*}{11} & Me' & Mentoniano tegumentar & 22 & OPMI & Oclusal do primeiro molar inferior \\
\hline & & & 23 & DPMI & Distal do primeiro molar inferior \\
\hline \multicolumn{3}{|r|}{ ESTRUTURA ESQUELÉTICA } & \multicolumn{3}{|r|}{ LINHAS E PLANOS } \\
\hline 24 & $N$ & Násio & 1 & & Plano de Frankfurt \\
\hline 25 & Or & Orbitário & 2 & & Linha N-perp \\
\hline 26 & $S$ & Sela & 3 & & Linha SN \\
\hline 27 & Po & Pório anatômico & 4 & & Plano mandibular GoGn \\
\hline 28 & $\mathrm{Pt}$ & Pterigóideo & 5 & & Plano mandibular GoMe \\
\hline 29 & ENA & Espinha nasal anterior & 6 & & Linha SGn \\
\hline 30 & ENP & Espinha nasal posterior & 7 & & Linha NA \\
\hline 31 & $A$ & Subespinhal & 8 & & Linha AP \\
\hline 32 & B & Supramentoniano & 9 & & PVT plano pterigoide vertical \\
\hline 33 & Pog & Pogônio & 10 & & Plano palatino \\
\hline 34 & Gn & Gnátio & 11 & & Linha BIS-AIS \\
\hline 35 & Me & Mentoniano & 12 & & Linha BII-All \\
\hline 36 & D & Ponto central da sínfise mentoniana & 13 & & Plano oclusal \\
\hline 37 & Go & Gônio & 14 & & Plano E de Ricketts \\
\hline \multirow[t]{2}{*}{38} & Co & Condílio & 15 & & Linha $\mathrm{H}$ de Holdaway \\
\hline & & & 16 & & Linha NB \\
\hline
\end{tabular}

Fonte: Elaborado pelo autor. 
Figura 4 - Traçado com as variáveis, linhas e planos obtidos através do software Dolphin Imaging 11.8

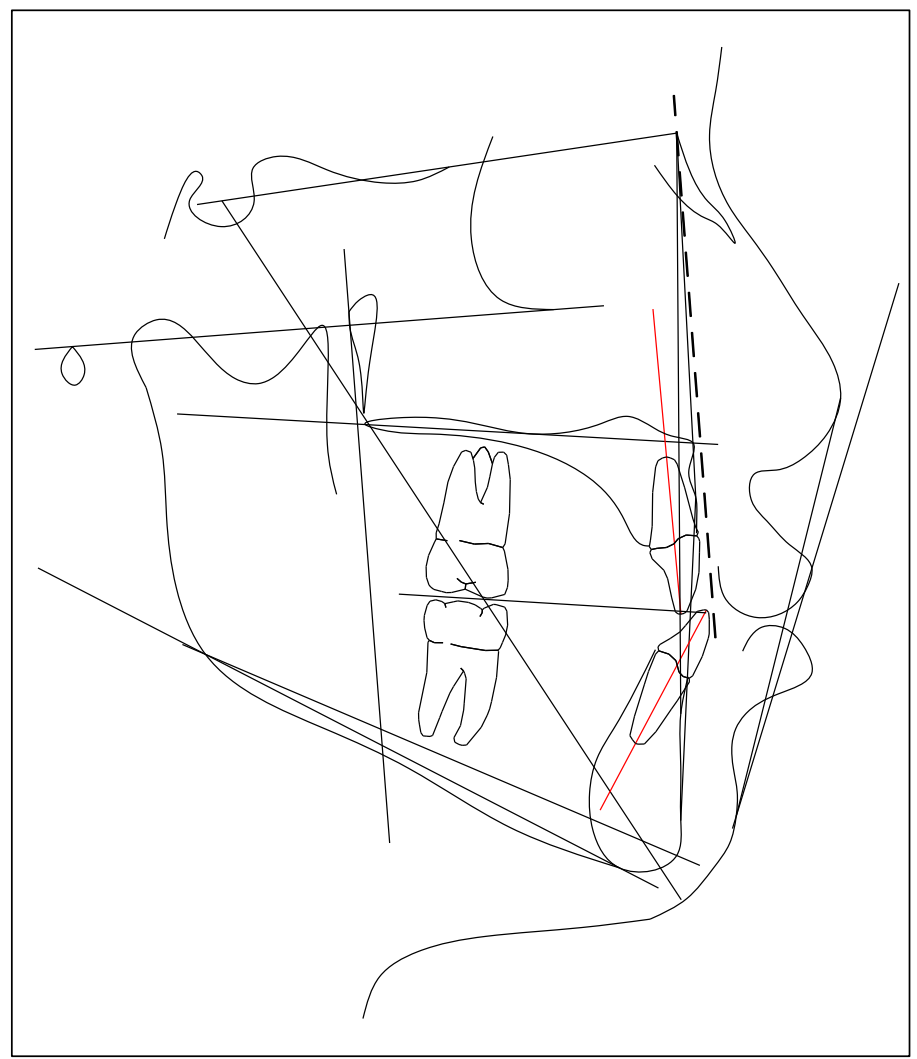

Fonte: Elaborada pelo autor.

Quadro 2 - Variáveis esqueléticas sagitais (medidas angulares da amostra)

\begin{tabular}{|l|l|l|}
\hline \multicolumn{3}{|c|}{ VARIAVEIS ESQUELÉTICAS (medidas angulares) } \\
\hline Componente Maxilar & SNA & Ângulo formado pela intersecção das linhas SN e NA \\
\hline Componente Mandibular & SNB & Ângulo formado pela intersecção das linhas SN e NB \\
\hline Maxilo-Mandibular & ANB & Ângulo formado pela intersecção da linha NA e NB \\
\hline Padrão De Crescimento & SN.GoGn & Ângulo formado pela linha SN com o plano GoGn \\
\hline
\end{tabular}

Fonte: Elaborado pelo autor.

Após esta etapa, a amostra foi dividida em grupos com a finalidade de encontrar alterações no crescimento craniofacial, a partir da relação com as técnicas utilizadas nas cirurgias primárias, tanto na queiloplastia (Spina vs. Millard), quanto na palatoplastia (Furlow vs. von Langembeck) e a fase cirúrgica que foi realizada a palatoplastia (9 a 12 meses vs 15 a 18 meses) e também verificar influências dos quatro cirurgiões que realizaram a cirurgia de lábio e palato $(C 1, C 2, C 3$ e $C 4)$, além de calcular a porcentagem de casos com prognostico ortodôntico-cirúrgico, 
compensatórios e limítrofes, associando às grandezas cefalométricas esqueléticas sagitais.

Quadro 3 - Amostra total de pacientes com FLPUC ( $n=349)$ divididos em subgrupos de acordo com as técnicas de queiloplatia e palatoplastia

\begin{tabular}{|c|c|c|c|c|c|}
\hline Queiloplastia & $\mathbf{n}$ & Palatoplastia & $\mathbf{n}$ & Grupos & $\mathbf{n}$ \\
\hline & & & & M-F & $\mathbf{8 5}$ \\
\hline MILLARD (M) & $\mathbf{1 8 5}$ & FURLOW (F) & $\mathbf{1 7 5}$ & & \\
\hline & & & & M-VL & 100 \\
\hline & & & & S-F & 75 \\
\hline SPINA (S) & 164 & VON LANGENBECK (VL) & 174 & & \\
\hline & & & & S-VL & 89 \\
\hline
\end{tabular}

Fonte: Elaborado pelo autor. 

4 FIRMA DE ANÁLISE DQS RESULTADOS 



\section{FORMA DE ANÁLISE DOS RESULTADOS}

\subsection{ERRO DO MÉTODO}

Através de um sorteio, 94 telerradiografias (26\% da amostra) foram selecionadas e um único avaliador calibrado realizou as demarcações dos pontos cefalométricos no software Dolphin Imaging 11.8 e, após um intervalo de 15 dias, foi feita novamente a demarcação destes pontos. O coeficiente de correlação intraclasse (ICC) foi calculado a partir da dupla determinação de cada marco cefalométrico para determinar o erro de identificação do marco usando uma ANOVA unidirecional para medidas repetidas.

O cálculo do erro do método entre o examinador foi calculado pelo teste $t$ pareado (HOUSTON, 1983) e de Dahlberg (DAHLBERG, 1940) que demonstra a variação média entre a primeira e a segunda medição.

O erro da análise do método para as medições de tecidos duros resultou em ICCs variando de 0, 99 a 1,00, indicando concordância muito boa a excelente. 0 erro casual de Dahberg (variação média entre a primeira e a segunda medição) encontrado foi: SNA $(0,38)$ SNB $(0,33)$; ANB $(0,25)$.

\subsection{ANÁLISE ESTATÍSTICA ENTRE OS GRUPOS}

Para os dados quanto ao crescimento sagital avaliou-se as variáveis primárias dependentes relacionadas à posição das bases esqueléticas. Os resultados obtidos do número total de indivíduos foram avaliados por meio de análise descritiva e depois analisados esses dados como três análises multivariadas com duas variáveis binárias independentes da queiloplastia (Spina vs. Millard) e da palatoplastia (Furlow vs. Von Langenbeck), da idade no momento da palatoplastia (9 a 12 meses vs 15 a 18 meses). O cirurgião foi avaliado como covariável e comparado utilizando quatro formas de Análise Multivariada de Desacordo na avaliação final.

O comportamento do crescimento sagital da maxila (SNA), mandíbula (SNB) e relação entre ambos (ANB) foram relacionadas com as variáveis como protocolos cirúrgicos e idade da cirurgia. 


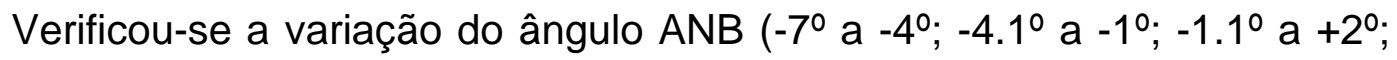
$\left.+2.1^{\circ} \mathrm{a}+4^{\circ}\right)$ para averiguar o percentual de casos com necessidade ortodônticocirúrgico, casos compensatórios. E casos limítrofes entre ortodontia e cirurgia (teste Qui quadrado). Considerou-se casos com necessidade ortodôntico cirúrgico, os casos com ANB bastante negativo

Todos os testes foram realizados com o programa Statistica (Version 7.0; StatSoft Inc., Tulsa, OK, USA), adotando-se um nível de significância de 5\%. 
5 RESULTADDS 



\section{RESULTADOS}

Os dados cefalométricos foram compilados e apresentados em forma de figuras, gráficos e tabelas a seguir.

Figura 5 - Gráfico de dispersão do angulo ANB na amostra total de pacientes com FLPU $(\mathrm{n}=349)$, operados do lábio pelas técnicas de Millard e Spina e do palato pelas técnicas de Von Langenbeck e Furlow

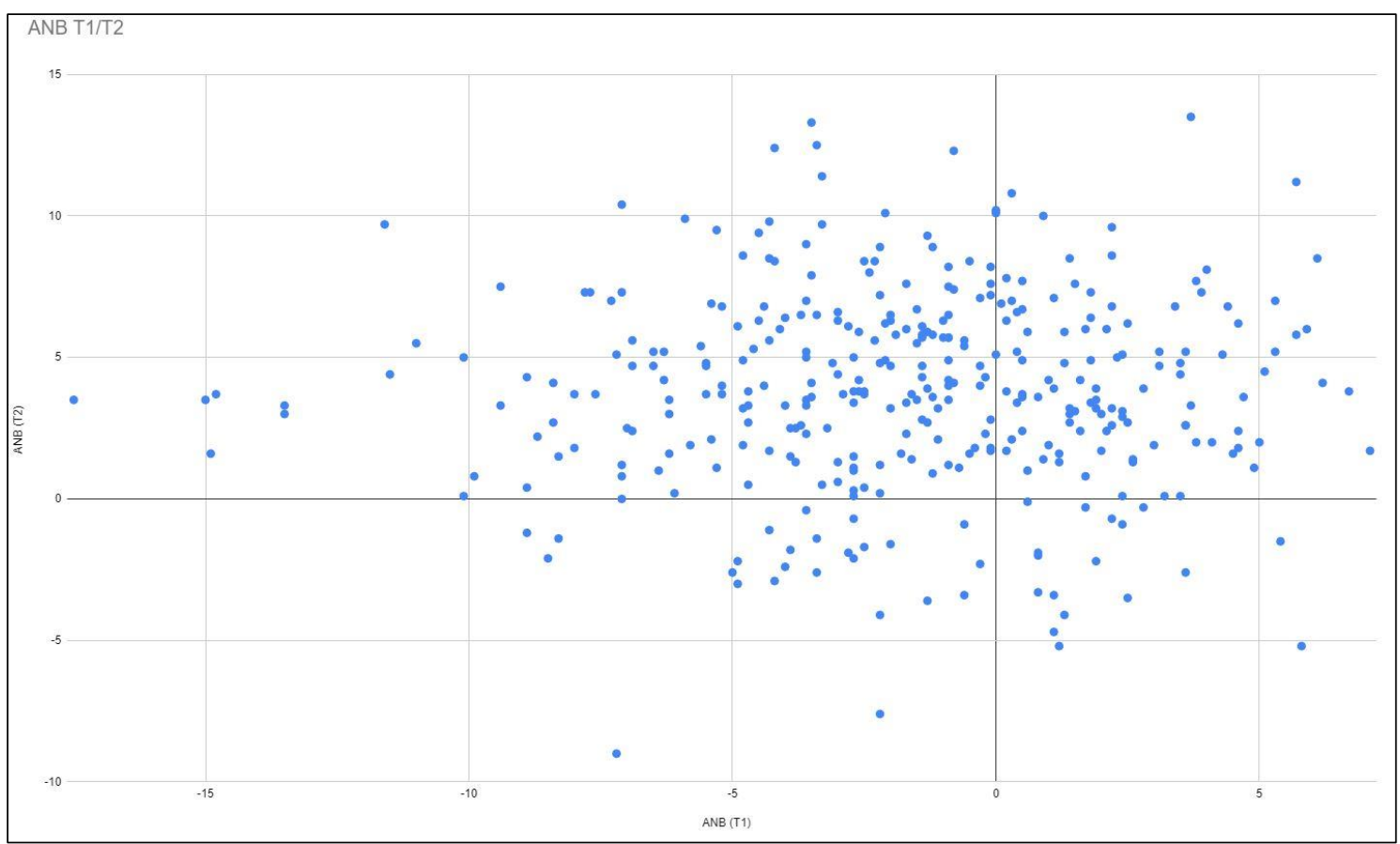

Fonte: Elaborada pelo autor.

Figura 6 - Gráfico da dispersão do ângulo SNA da amostra total $(n=349)$, mostrando o comportamento da maxila no sentido sagital. Comparação da fase T1 (na dentadura mista) antes do tratamento ortodôntico com a fase T2 (dentadura permanente após tratamento ortodôntico com a fase T2 (dentadura permanente após tratamento ortodôntico/ortopédico + EOA)

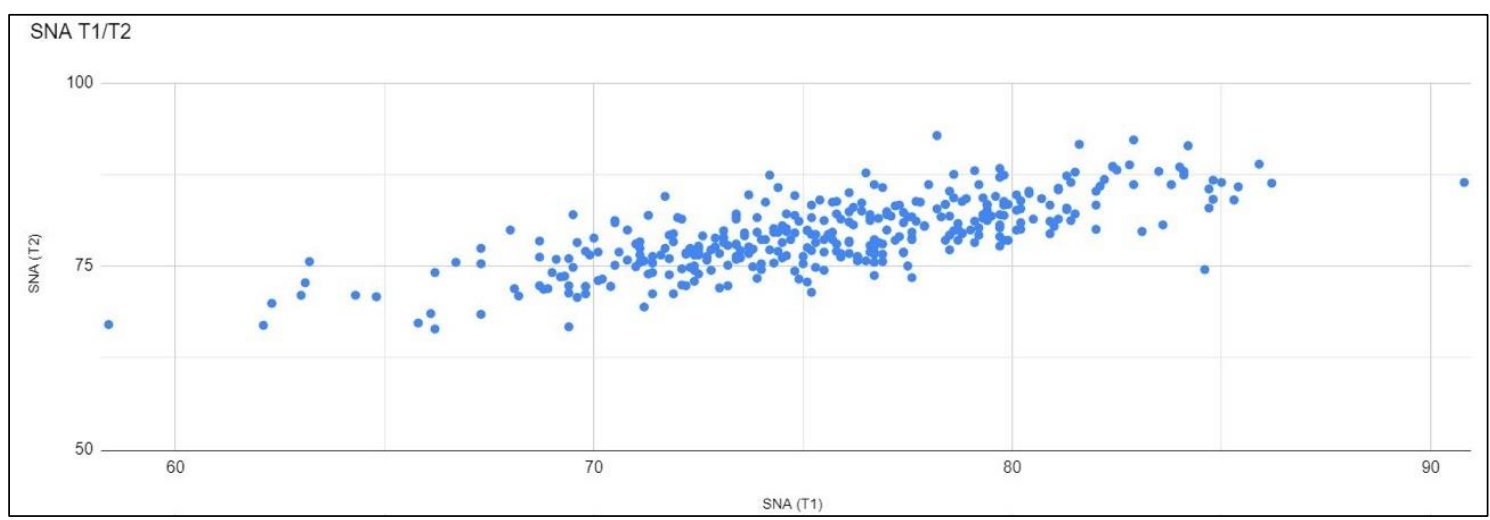

Fonte: Elaborada pelo autor. 
Figura 7 - Gráfico da dispersão do ângulo SNB da amostra total $(n=349)$, mostrando o comportamento da mandíbula no sentido sagital. Comparação da fase T1 (na dentadura mista) antes do tratamento ortodôntico com a fase T2 (dentadura permanente após tratamento ortodôntico/ortopédico + EOA)

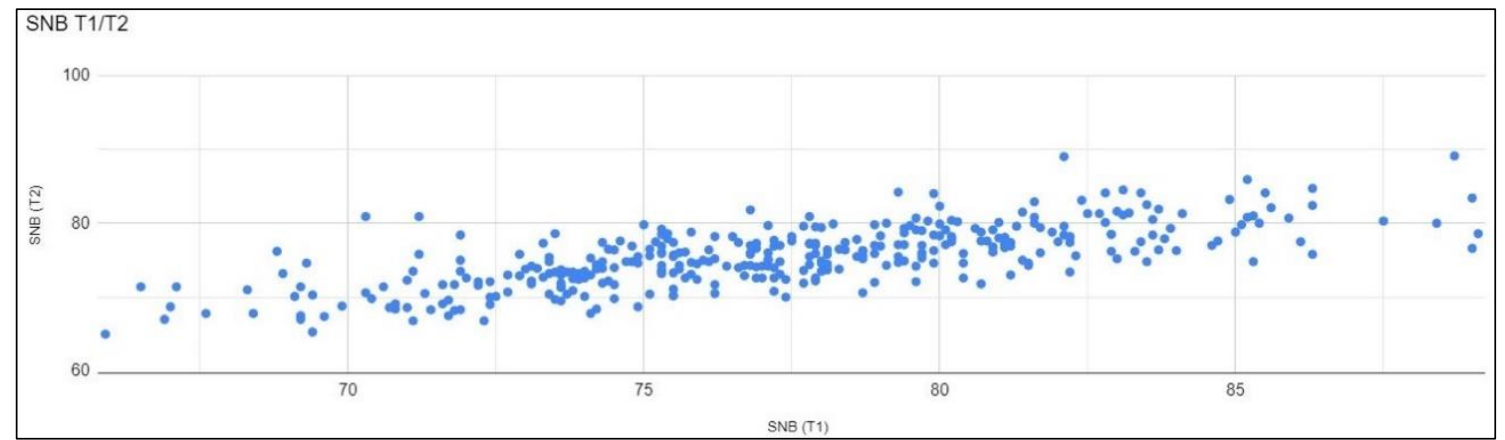

Fonte: Elaborada pelo autor.

Figura 8 - Distribuição do ângulo ANB na amostra total de pacientes com FLPU ( $n=349)$, avaliados na dentadura mista (T1) e na dentadura permanente (T2)

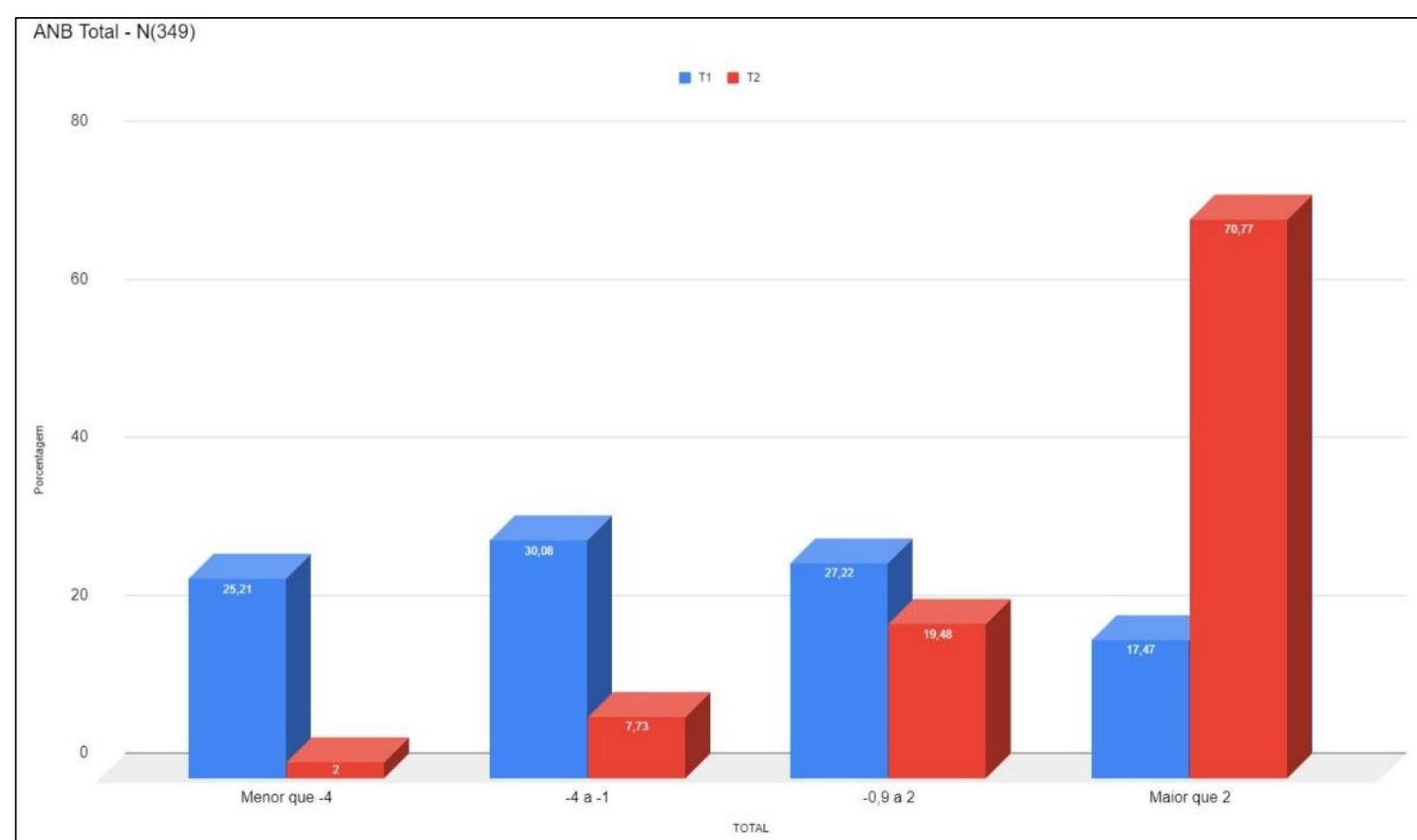

Nota: Percentual de casos de ANB variando de $-7^{\circ}$ a $-1^{\circ}$ apresentam Classe III esquelética $e$ discrepância negativa entre posição maxilar e mandibular.

Fonte: Elaborada pelo autor. 
Figura 9 - Variação do ângulo SNA da dentadura mista (T1) até a dentadura permanente (T2) na amostra total de FTIU $(n=349)$

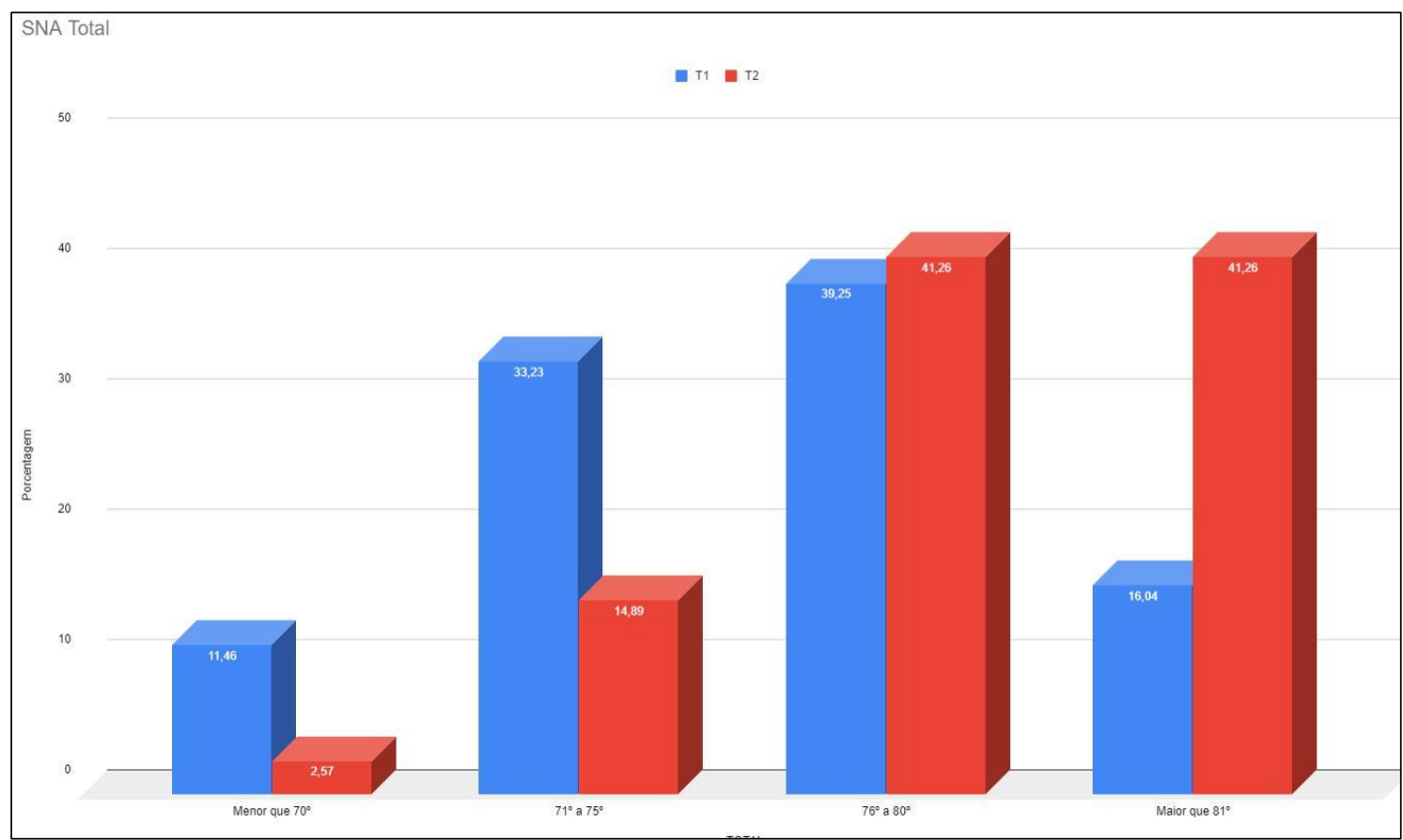

Nota: Quanto maior o percentual de SNA $<75^{\circ}$ indica deficiência sagital da maxila.

Fonte: Elaborada pelo autor.

Tabela 1 - Medidas cefalométricas angulares (médias) referentes à posição sagital da maxila (SNA), mandíbula (SNB) e relação entre elas (ANB) em pacientes com FLPUC submetidos à queiloplastia [Millard (M) e Spina (S)] e palatoplastia [Von Langenbeck (VL) e Furlow (F)], avaliados na fase T1 (dentadura mista) e T2 (dentadura permanente a partir de 14 anos)

\begin{tabular}{cccccccccccccc}
\hline Queiloplastia & T1 & $\mathbf{M}$ & & T2 & $\mathbf{M}$ & & $\mathbf{T 1}$ & $\mathbf{S}$ & & T2 & $\mathbf{S}$ & & \\
\hline Medidas & $\mathbf{n}$ & Média & DP & $\mathbf{n}$ & Média & DP & $\mathbf{n}$ & Média & DP & $\mathbf{n}$ & Média & DP & $\mathbf{p}$ \\
SNA & 185 & 75,77 & 4,86 & 185 & 79,64 & 4,88 & 164 & 75,32 & 4,6 & 164 & 78,89 & 4,68 & 0,3 \\
SNB & 185 & 77,43 & 4,55 & 185 & 75,77 & 4,19 & 164 & 77,17 & 4,58 & 164 & 75,2 & 3,9 & 0,6 \\
ANB & 185 & $-1,66$ & 4,12 & 185 & 3,88 & 3,39 & 164 & $-1,84$ & 4,06 & 164 & 3,69 & 3,7 & 0,55 \\
\hline
\end{tabular}

\begin{tabular}{cccccccccccccc}
\hline Palatoplastia & T1 & VL & & T2 & VL & & T1 & $\mathbf{F}$ & & T2 & F & \\
\hline Medidas & $\mathbf{n}$ & Média & DP & $\mathbf{n}$ & Média & DP & $\mathbf{n}$ & Média & DP & $\mathbf{n}$ & Média & DP & $\mathbf{p}$ \\
SNA & 175 & 75,09 & 4,81 & 175 & 78,68 & 4,7 & 174 & 76,03 & 4,62 & 174 & 79,9 & 4,83 & 0,06 \\
SNB & 175 & 77,35 & 4,7 & 175 & 75,26 & 4,06 & 174 & 77,26 & 4,43 & 174 & 75,75 & 4,06 & 0,94 \\
ANB & 175 & $-2,26$ & 4,21 & 175 & 3,42 & 3,74 & 174 & $-1,22$ & 3,89 & 174 & 4,16 & 3,28 & $\mathbf{0 , 0 2}$ \\
\hline
\end{tabular}

Fonte: Elaborada pelo autor. 
Figura 10 - Medidas cefalométricas angulares referentes à relação maxilomandibular (ANB) em pacientes com FTIU operados do lábio pelas técnicas de Millard $(n=185)$ ) e Spina $(n=164)$ avaliados na fase T1 e T2

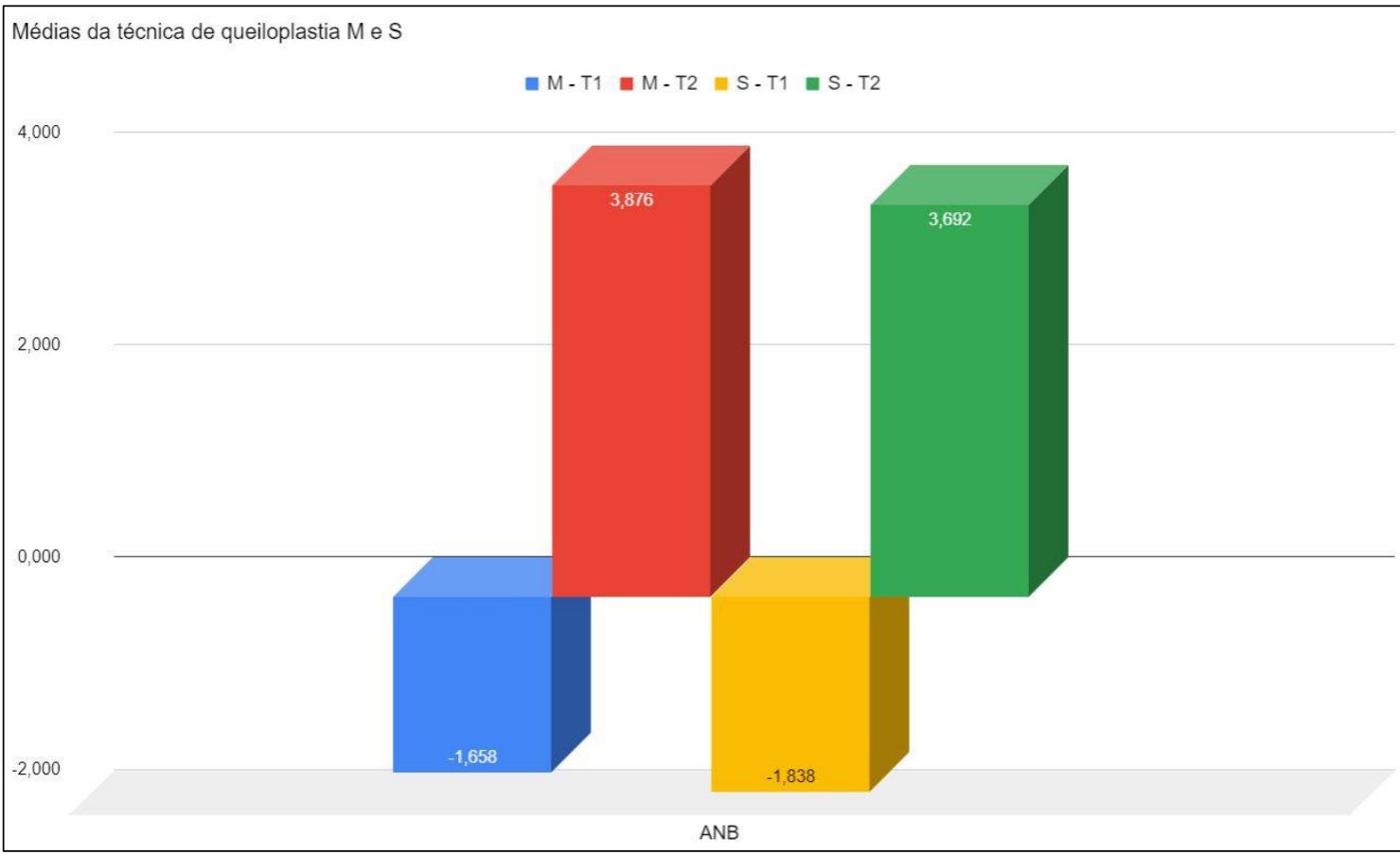

Nota: Não houve diferença estatisticamente significante.

Fonte: Elaborada pelo autor.

Figura 11 - Medidas cefalométricas angulares referentes à posição sagital maxilo mandibular (ANB) em pacientes com FTIU operados do palato pelas técnicas de Von Langenbeck (VL: $n=175)$ e Furlow ( $F: n=174)$, avaliados na fase T1 e T2

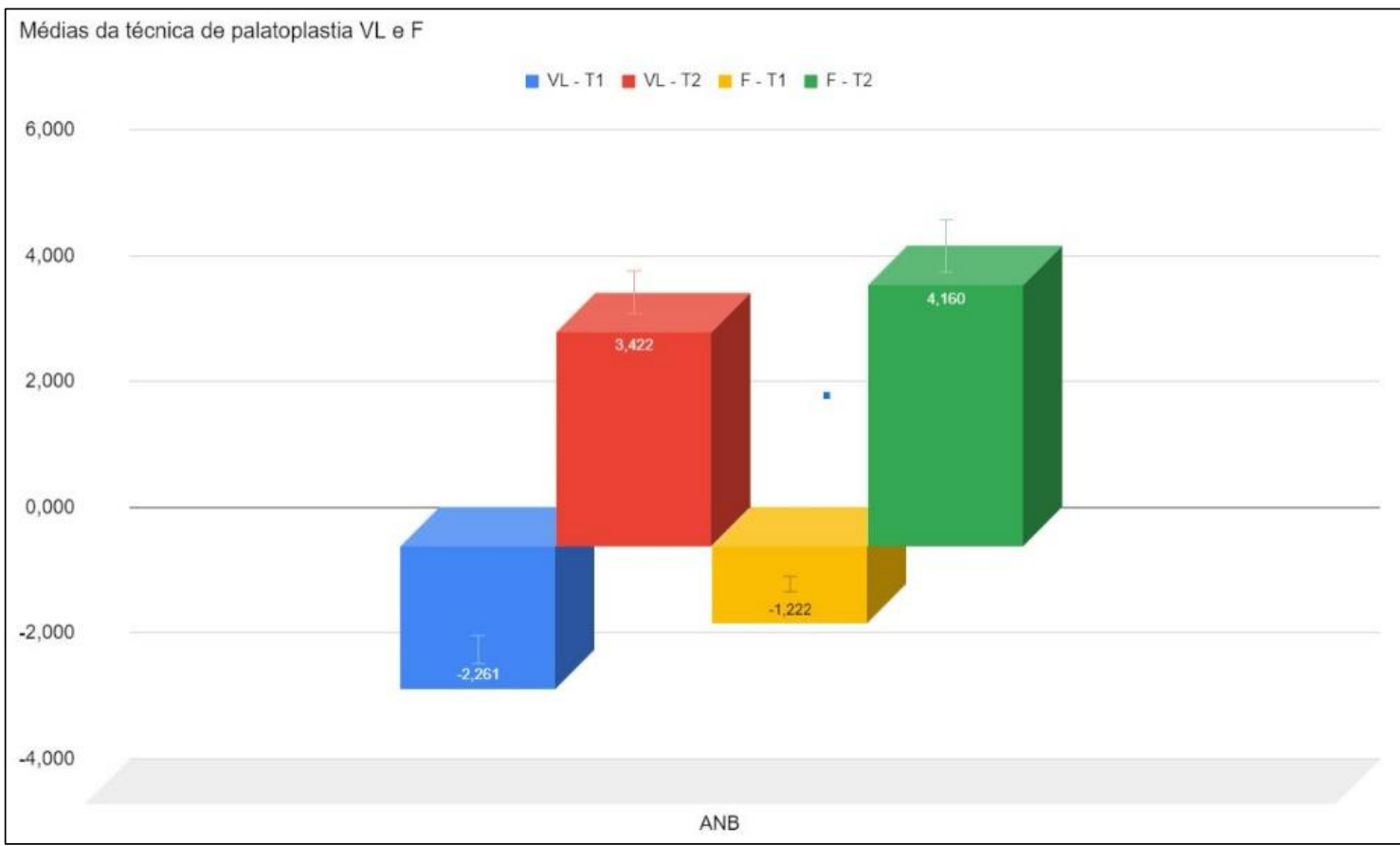

Nota: $p=0,02^{*}$ para as técnicas de F e VL em T1.

Fonte: Elaborada pelo autor. 
Figura 12 - Média dos Ângulos ANB e SNA dos grupos submetidos à protocolos distintos de queiloplastias (Spina vs Millard) em T1, na dentadura mista, antes do tratamento ortodôntico e EOA, e em T2 (na dentadura permanente após o tratamento ortodôntico)

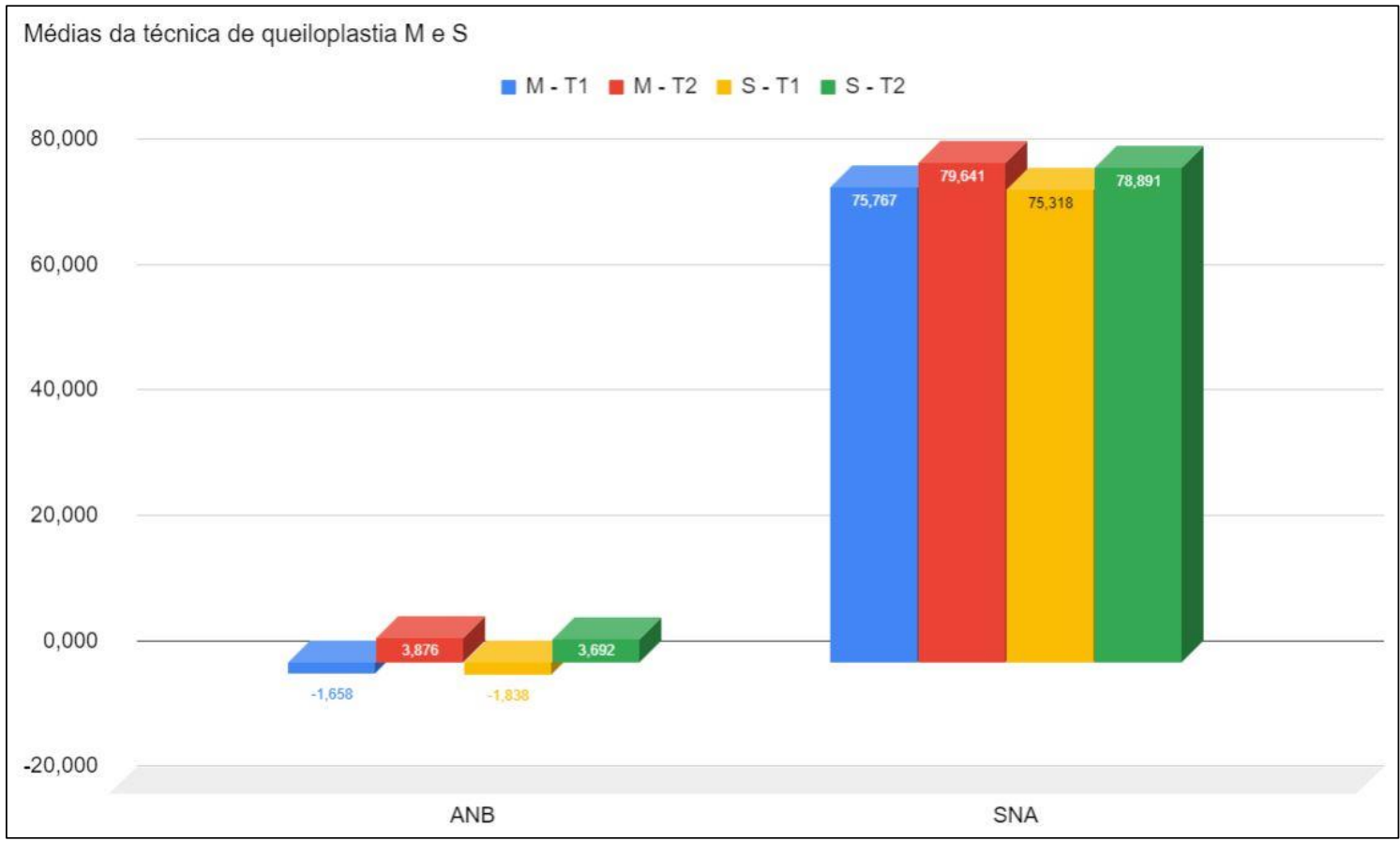

Fonte: Elaborada pelo autor.

Figura 13 - Média dos Ângulos ANB e SNA dos grupos submetidos à protocolos distintos de palatoplastias ( $F$ vs VL) em T1, na dentadura mista antes do tratamento ortodôntico e EOA, e em T2 (na dentadura permanente após o tratamento ortodôntico)

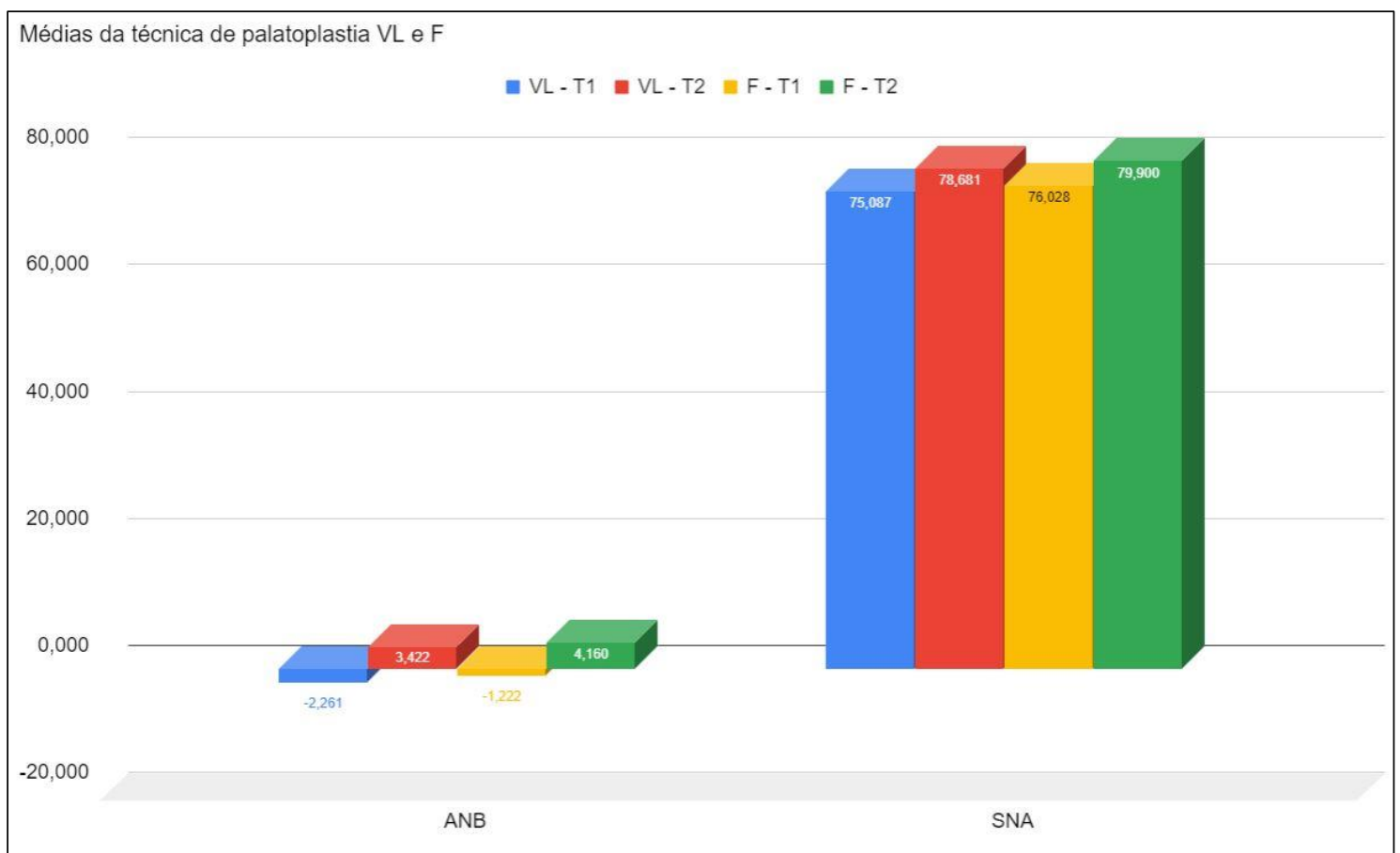

Fonte: Elaborada pelo autor. 
Tabela 2 - Medidas cefalométricas angulares referentes à posição sagital da maxila (SNA), mandíbula (SNB) e relação entre elas (ANB) em pacientes com FLPUC submetidos à queiloplatia pela técnica de Millard (M) e Spina (S) e palatoplastias pelas técnica de Von Langenbeck (VL) e Furlow (F) em fase T1 (dentadura mista) e T2 (dentadura permanente)

\begin{tabular}{|c|c|c|c|c|c|c|c|c|c|c|c|c|c|}
\hline $\mathrm{T} 1$ & & M-VL & & & M-F & & & S-VL & & & S-F & & \\
\hline & $\mathbf{n}$ & Média & DP & $\mathbf{n}$ & Média & DP & $\mathbf{n}$ & Média & DP & $\mathbf{n}$ & Média & DP & $p$ \\
\hline SNA & 100 & 75,16 & 4,92 & 85 & 76,48 & 4,72 & 75 & 74,99 & 4,71 & 89 & 75,59 & 4,51 & 0,48 \\
\hline SNB & 100 & 77,74 & 4,71 & 85 & 77,06 & 4,35 & 75 & 76,84 & 4,66 & 89 & 77,44 & 4,52 & 0,20 \\
\hline ANB & 100 & $-2,58$ & 4,51 & 85 & $-0,58$ & 3,32 & 75 & $-1,84$ & 3,78 & 89 & $-1,84$ & 4,30 & $0,02^{*}$ \\
\hline \multirow[t]{2}{*}{ T2 } & & M-VL & & & M-F & & & S-VL & & & S-F & & \\
\hline & $\mathbf{n}$ & Média & DP & $\mathbf{n}$ & Média & DP & $\mathbf{n}$ & Média & DP & $\mathbf{n}$ & Média & DP & $p$ \\
\hline SNA & 100 & 78,79 & 4,66 & 85 & 80,64 & 4,96 & 75 & 78,54 & 4,77 & 89 & 79,19 & 4,62 & 0,25 \\
\hline SNB & 100 & 75,55 & 4,12 & 85 & 76,03 & 4,28 & 75 & 74,87 & 3,97 & 89 & 75,47 & 3,85 & 0,79 \\
\hline ANB & 100 & 3,24 & 3,59 & 85 & 4,62 & 2,99 & 75 & 3,66 & 3,94 & 89 & 3,72 & 3,50 & 0,25 \\
\hline
\end{tabular}

\begin{tabular}{lcccc}
\hline \multicolumn{1}{c}{ T1 - Estatística ANOVA } & Degr. of & SNA & SNB & ANB \\
\cline { 2 - 6 } & Freedom & $\mathbf{p}$ & $\mathbf{p}$ & $\mathbf{p}$ \\
\hline Técnica lábio $(\mathrm{M}=0, \mathrm{~S}=1)$ & 1 & 0,30 & 0,60 & 0,55 \\
Técnica palato $(\mathrm{VL}=0, \mathrm{~F}=1)$ & 1 & 0,06 & 0,94 & 0,02 \\
Técnica lábio $(\mathrm{M}=0, \mathrm{~S}=1){ }^{*}$ Técnica palato $(\mathrm{VL}=0, \mathrm{~F}=1)$ & 1 & 0,48 & 0,20 & $\mathbf{0 , 0 2}$ \\
\hline
\end{tabular}

Nota: No teste de Tukey detectou-se diferença estatística no Ângulo ANB entre as técnicas de M-VL e M-F em T1.

Fonte: Elaborada pelo autor.

Tabela 3 - Teste de Tukey - variável ANB

\begin{tabular}{|c|c|c|c|c|c|c|c|}
\hline $\begin{array}{c}\text { T1 } \\
\text { Tukey HSD test } \\
\text { ANB } \\
\end{array}$ & $\begin{array}{l}\text { Técnica lábio } \\
(\mathrm{M}=0, \mathrm{~S}=1)\end{array}$ & $\begin{array}{l}\text { Técnica palato } \\
(\mathrm{VL}=0, \mathrm{~F}=1)\end{array}$ & $\{1\}$ & & & 3\} & $\{4\}$ \\
\hline 1 & 0 & 0 & & & & 63 & 0,59 \\
\hline 2 & 0 & 1 & 0,00 & & & 20 & 0,17 \\
\hline 3 & 1 & 0 & 0,63 & & & & 1,00 \\
\hline 4 & 1 & 1 & 0,59 & & & 00 & \\
\hline \multirow{2}{*}{\multicolumn{3}{|c|}{ T2 - Estatística ANOVA }} & & & & SNB & ANE \\
\hline & & & \multicolumn{2}{|c|}{ Freedom } & & $\mathbf{p}$ & $\mathbf{p}$ \\
\hline \multirow{2}{*}{\multicolumn{3}{|c|}{$\begin{array}{l}\text { Técnica lábio }(\mathrm{M}=0, \mathrm{~S}=1) \\
\text { Técnica palato }(\mathrm{VL}=0, \mathrm{~F}=1)\end{array}$}} & \multicolumn{2}{|c|}{1} & & 0,25 & 0,43 \\
\hline & & & \multirow{2}{*}{\multicolumn{2}{|c|}{$\begin{array}{l}1 \\
1\end{array}$}} & & 0,22 & 0,05 \\
\hline \multicolumn{3}{|c|}{ Técnica lábio $(M=0, S=1)^{*}$ Técnica palato $(V L=0, F=1)$} & & & & 0,79 & 0,07 \\
\hline
\end{tabular}

Fonte: Elaborada pelo autor. 
Figura 14 - Média dos Ângulos ANB dos grupos submetidos à protocolos distintos de queiloplastias e palatoplastias (SF; SVL; MF; MVL), em T1, na dentadura mista, antes do tratamento ortodôntico e EOA, e em T2 (na dentadura permanente após o tratamento ortodontico/ ortopédico + EOA)

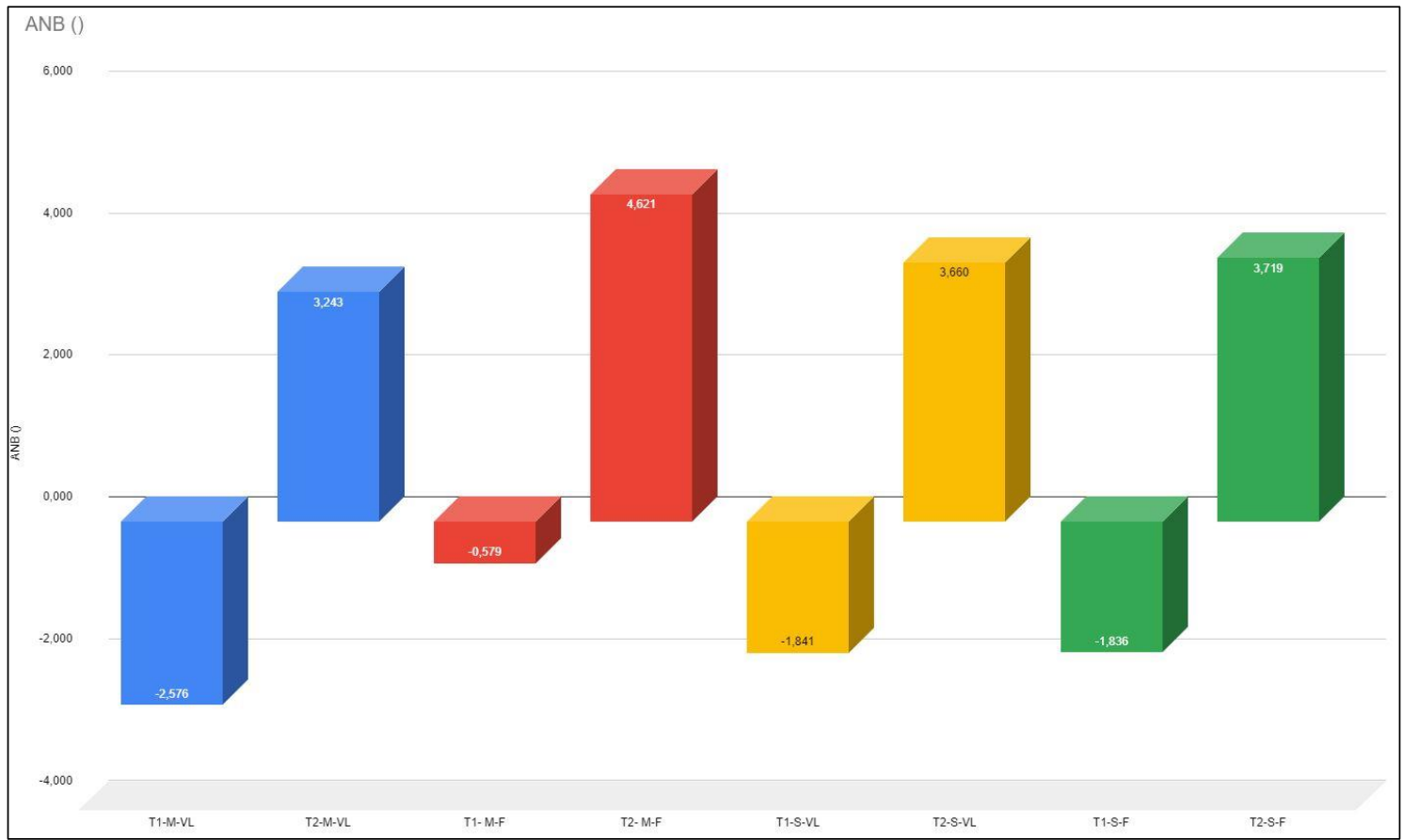

Nota: Houve diferença estatistica entre a técnica de MF e MVL em T1 $\left(p=0,02^{*}\right)$.

Fonte: Elaborada pelo autor.

Figura 15 - Média dos ângulos SNA dos grupos submetidos à protocolos distintos de queiloplastias e palatoplastias (SF; SVL; MF; MVL), em T1, na dentadura mista (6-8 anos), antes do tratamento ortodôntico e EOA, e em T2 (na dentadura permanente após o tratamento ortodôntico/ortopédico + EOA)

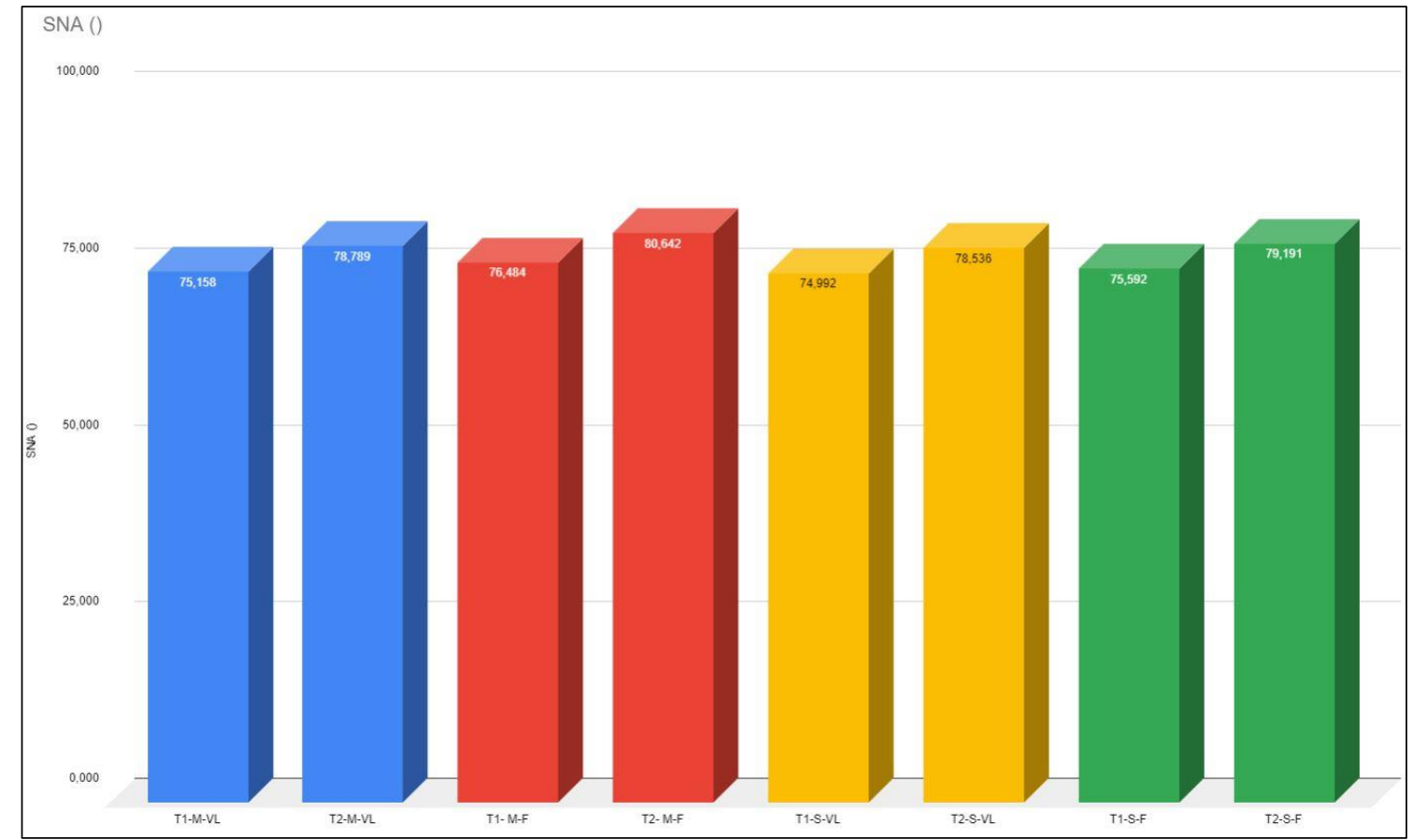

Fonte: Elaborada pelo autor. 
Figura 16 - Distribuição dos ângulos ANB de acordo com diferentes protocolos cirúrgicos de queiloplastias e palatoplastias (MF; MVL; SF; SVL), em T1 e T2

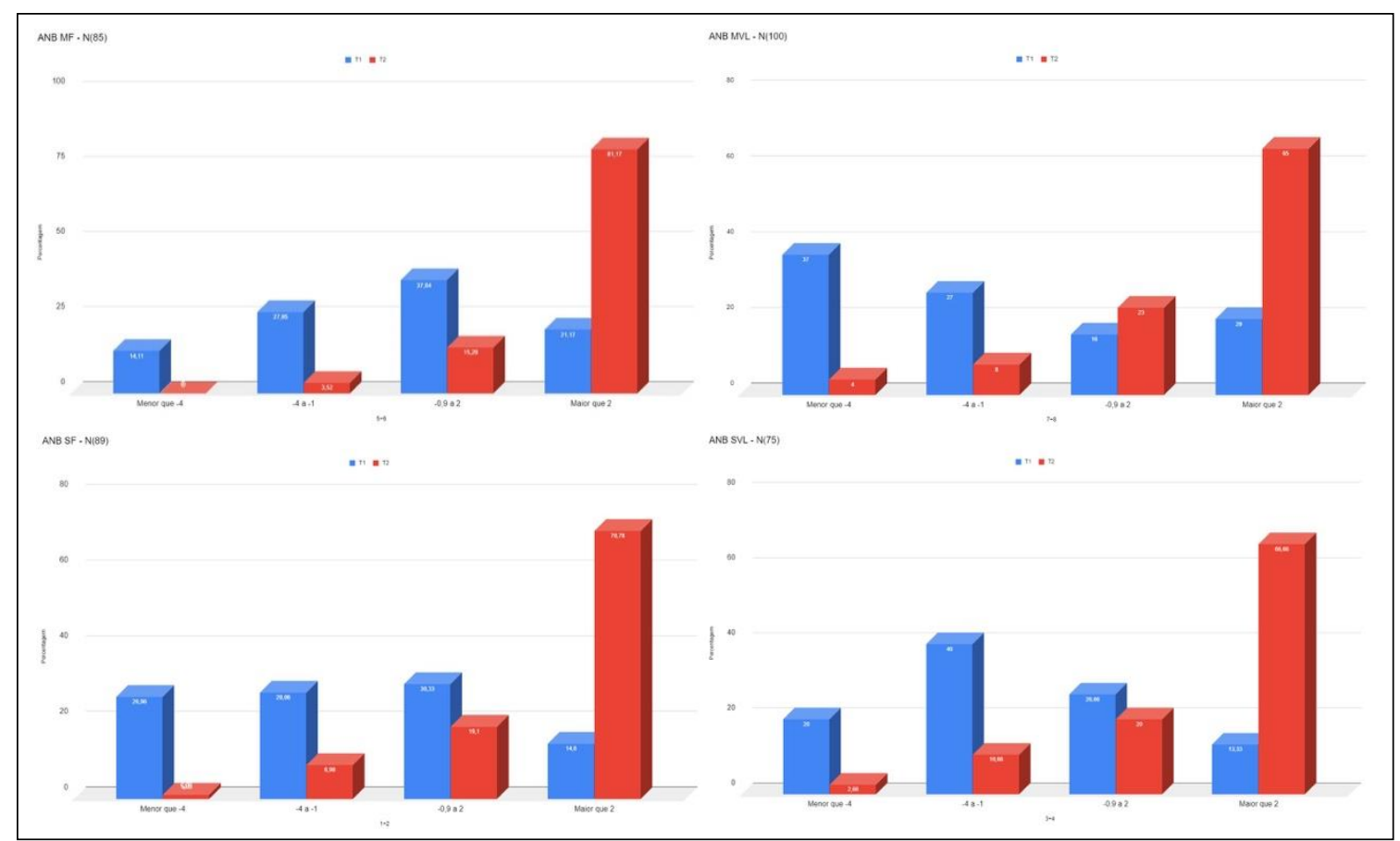

Nota: Quanto maior o percentual de casos com ANB $<-1^{\circ}$ a $-7^{\circ}-$ indica relação maxilomandibular discrepante de Classe III esquelética.

Fonte: Elaborada pelo autor.

Figura 17 - Percentual de Distribuição dos ângulos SNA nos diferentes protocolos cirúrgicos de queiloplastias e palatoplastias (SF; SVL; MF; MVL), em T1 e T2

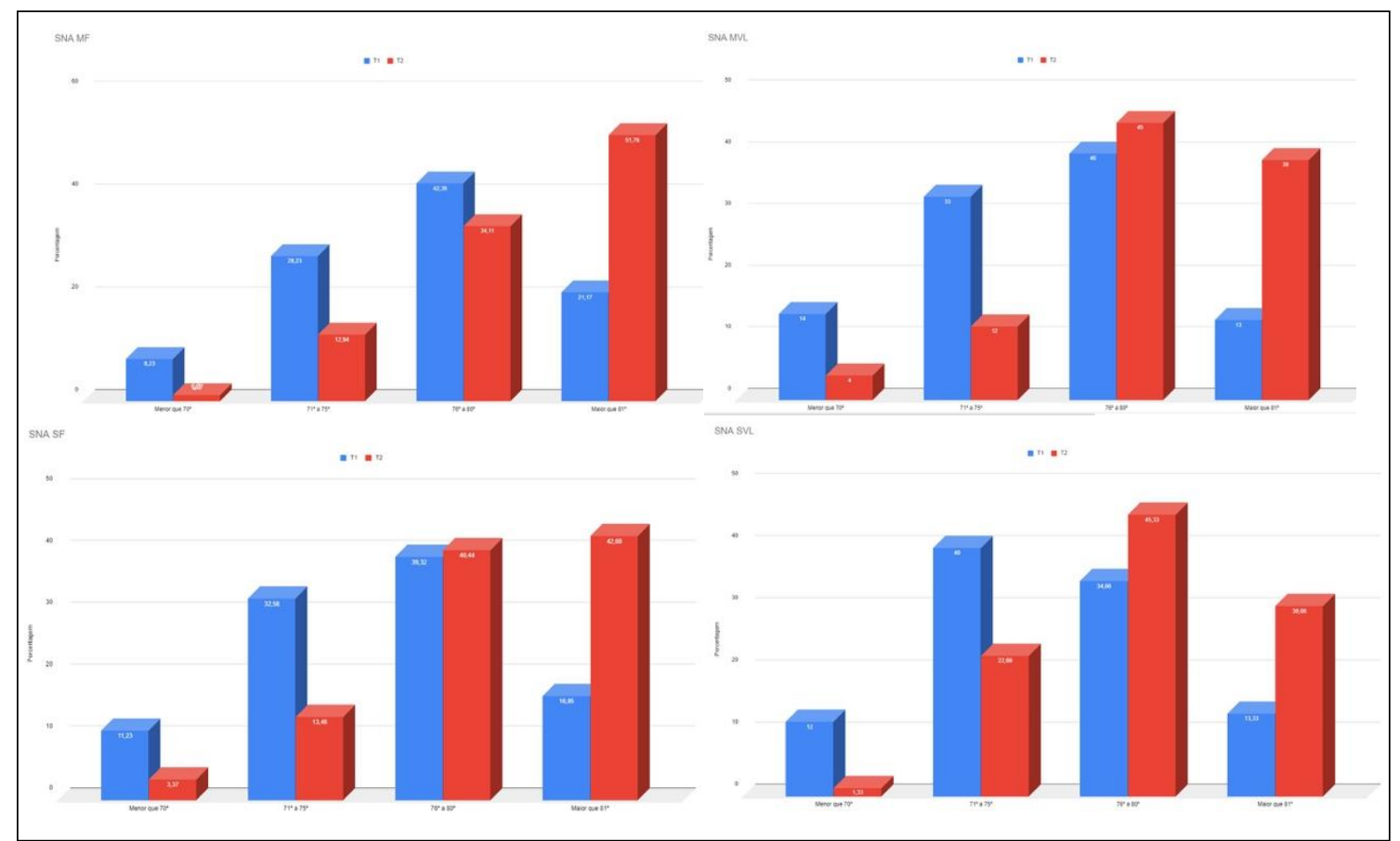

Nota: Quanto maior o Percentual de casos com SNA $<75^{\circ}$ indica deficiência da relação sagital da maxila.

Fonte: Elaborada pelo autor. 
Tabela 4 - Comparação entre Palatoplastia Precoce versus Tardio. Medidas angulares SNA, SNB, ANB em pacientes FLPUC submetidos à palatoplastia em um tempo em idade precoce (912 meses) e tardio (15-18 meses) nas fases T1 (dentadura decídua e mista) e T2 (permanente)

\begin{tabular}{|c|c|c|c|c|c|c|c|c|c|c|c|}
\hline \multirow{2}{*}{\multicolumn{2}{|c|}{$\begin{array}{c}\text { T1 } \\
\text { Medidas } \\
\text { Precoce (0) } \\
\text { Tardio (1) }\end{array}$}} & \multicolumn{4}{|c|}{ T1 } & \multicolumn{6}{|c|}{ T1 } \\
\hline & & \multicolumn{2}{|c|}{$\begin{array}{c}\mathbf{n} \\
\text { Precoce } \\
(0)\end{array}$} & $\begin{array}{l}\text { Palato } \\
\text { Precoce } \\
\text { Média }\end{array}$ & $\begin{array}{c}\text { Erro } \\
\text { Desvio }\end{array}$ & $\begin{array}{l}\text { Erro } \\
\text { padrão da } \\
\text { média }\end{array}$ & \multicolumn{2}{|c|}{$\begin{array}{c}n \\
\text { Tardio } \\
\text { (1) }\end{array}$} & $\begin{array}{l}\text { Palato } \\
\text { tardio } \\
\text { Média }\end{array}$ & $\begin{array}{c}\text { Erro } \\
\text { Desvio }\end{array}$ & $\begin{array}{l}\text { Erro } \\
\text { padrão da } \\
\text { média }\end{array}$ \\
\hline SN & & 171 & & 75,05 & 4,96 & 0,38 & 178 & & 76,04 & 4,47 & 0,34 \\
\hline SI & & 171 & & 77,26 & 4,54 & 0,35 & 178 & & 77,34 & 4,59 & 0,34 \\
\hline AN & & 171 & & $-2,21$ & 3,99 & 0,31 & 178 & & $-1,30$ & 4,14 & 0,31 \\
\hline \multicolumn{2}{|c|}{ T2 } & \multicolumn{4}{|c|}{ T2 } & \multicolumn{6}{|c|}{ T2 } \\
\hline \multicolumn{2}{|c|}{$\begin{array}{c}\text { Medidas } \\
\text { Precoce (0) } \\
\text { Tardio (1) }\end{array}$} & \multicolumn{2}{|l|}{$n$} & $\begin{array}{l}\text { Palato } \\
\text { Precoce } \\
\text { Média }\end{array}$ & $\begin{array}{c}\text { Erro } \\
\text { Desvio }\end{array}$ & $\begin{array}{c}\text { Erro } \\
\text { padrão da } \\
\text { média }\end{array}$ & \multicolumn{2}{|c|}{$\stackrel{\mathbf{n}}{\text { Tardio (1) }}$} & $\begin{array}{l}\text { Palato } \\
\text { tardio } \\
\text { Média }\end{array}$ & $\begin{array}{c}\text { Erro } \\
\text { Desvio }\end{array}$ & $\begin{array}{c}\text { Erro } \\
\text { padrão da } \\
\text { média }\end{array}$ \\
\hline \multicolumn{2}{|c|}{ SNA } & \multicolumn{2}{|l|}{171} & 79,02 & 5,08 & 0,39 & \multicolumn{2}{|l|}{178} & 79,55 & 4,51 & 0,34 \\
\hline \multicolumn{2}{|c|}{ SNB } & \multicolumn{2}{|l|}{171} & 75,44 & 4,19 & 0,32 & \multicolumn{2}{|l|}{178} & 75,56 & 3,95 & 0,30 \\
\hline \multicolumn{2}{|c|}{ ANB } & \multicolumn{2}{|l|}{171} & 3,58 & 3,62 & 0,28 & 178 & & 3,99 & 3,45 & 0,26 \\
\hline & Pala & top. & & T1 & & & & & T2 & & \\
\hline & $\begin{array}{r}\text { Prec } \\
(0 \\
\text { Tardi }\end{array}$ & $\begin{array}{l}\text { oce } \\
\text { ) } \\
\text { o (1) }\end{array}$ & $\mathrm{n}$ & $\begin{array}{c}\text { T1 } \\
\text { Média }\end{array}$ & $\begin{array}{c}\text { Erro } \\
\text { Desvio }\end{array}$ & $\begin{array}{c}\text { Erro } \\
\text { padrão } \\
\text { da } \\
\text { média }\end{array}$ & $p$ & $\mathrm{n}$ & $\begin{array}{c}\text { T2. } \\
\text { Média }\end{array}$ & $\begin{array}{c}\text { Erro } \\
\text { Desvio }\end{array}$ & $\begin{array}{c}\text { Erro } \\
\text { padrão } \\
\text { da } \\
\text { média }\end{array}$ \\
\hline SNA & 0 & & 171 & 75,053 & 4,9619 & 0,3794 & 0,052 & 171 & 79,021 & 5,0759 & 0,3882 \\
\hline & 1 & & 178 & 76,039 & 4,4721 & 0,3352 & 0,052 & 178 & 79,546 & 4,5101 & 0,3380 \\
\hline SNB & 0 & & 171 & 77,264 & 4,5378 & 0,3470 & 0,874 & 171 & 75,444 & 4,1871 & 0,3202 \\
\hline & 1 & & 178 & 77,342 & 4,5943 & 0,3444 & 0,874 & 178 & 75,556 & 3,9515 & 0,2962 \\
\hline ANB & 0 & & 171 & $-2,207$ & 3,9907 & 0,3052 & 0,037 & 171 & 3,582 & 3,6172 & 0,2766 \\
\hline & 1 & & 178 & $-1,297$ & 4,1355 & 0,3100 & 0,037 & 178 & 3,989 & 3,4489 & 0,2585 \\
\hline & $\mathbf{Z}$ & Sig. & $t$ & df & $p$ & $\begin{array}{c}\text { Diferença } \\
\text { média }\end{array}$ & $\begin{array}{r}\text { Err } \\
\text { padr } \\
\text { de } \\
\text { difere }\end{array}$ & & $\begin{array}{r}95 \% \text { Inte } \\
\text { de Confia } \\
\text { Diferer }\end{array}$ & $\begin{array}{l}\text { ervalo } \\
\text { ança da } \\
\text { nça }\end{array}$ & $p$ \\
\hline SNA & 2,832 & 0,093 & $-1,951$ & 347 & 0,052 & $-0,9855$ & 0,50 & & $-1,979$ & 93 & 0,0082 \\
\hline SNA & & & $-1,947$ & 339,993 & 0,052 & $-0,9855$ & 0,50 & & $-1,981$ & 314 & 0,0103 \\
\hline SNB & 0,356 & 0,551 & $-0,159$ & 347 & 0,874 & $-0,0778$ & 0,48 & & $-1,03 s$ & 396 & 0,8839 \\
\hline SNB & & & $-0,159$ & 346,731 & 0,874 & $-0,0778$ & 0,48 & & $-1,039$ & 394 & 0,8837 \\
\hline ANB & 0,804 & 0,370 & $-2,090$ & 347 & 0,037 & $-0,9098$ & 0,43 & & $-1,766$ & 60 & $-0,0537$ \\
\hline ANB & & & $-2,092$ & 346,993 & 0,037 & $-0,9098$ & 0,43 & & $-1,765$ & 54 & $-0,0543$ \\
\hline
\end{tabular}

Fonte: Elaborada pelo autor. 
Figura 18 - Média dos Ângulos SNA dos grupos submetidos à protocolos distintos de queiloplastias e palatoplastias (SF; SVL; MF; MVL), com o fechamento do palato entre 9-12 meses $(P)$ e entre 15-18 meses $(T)$

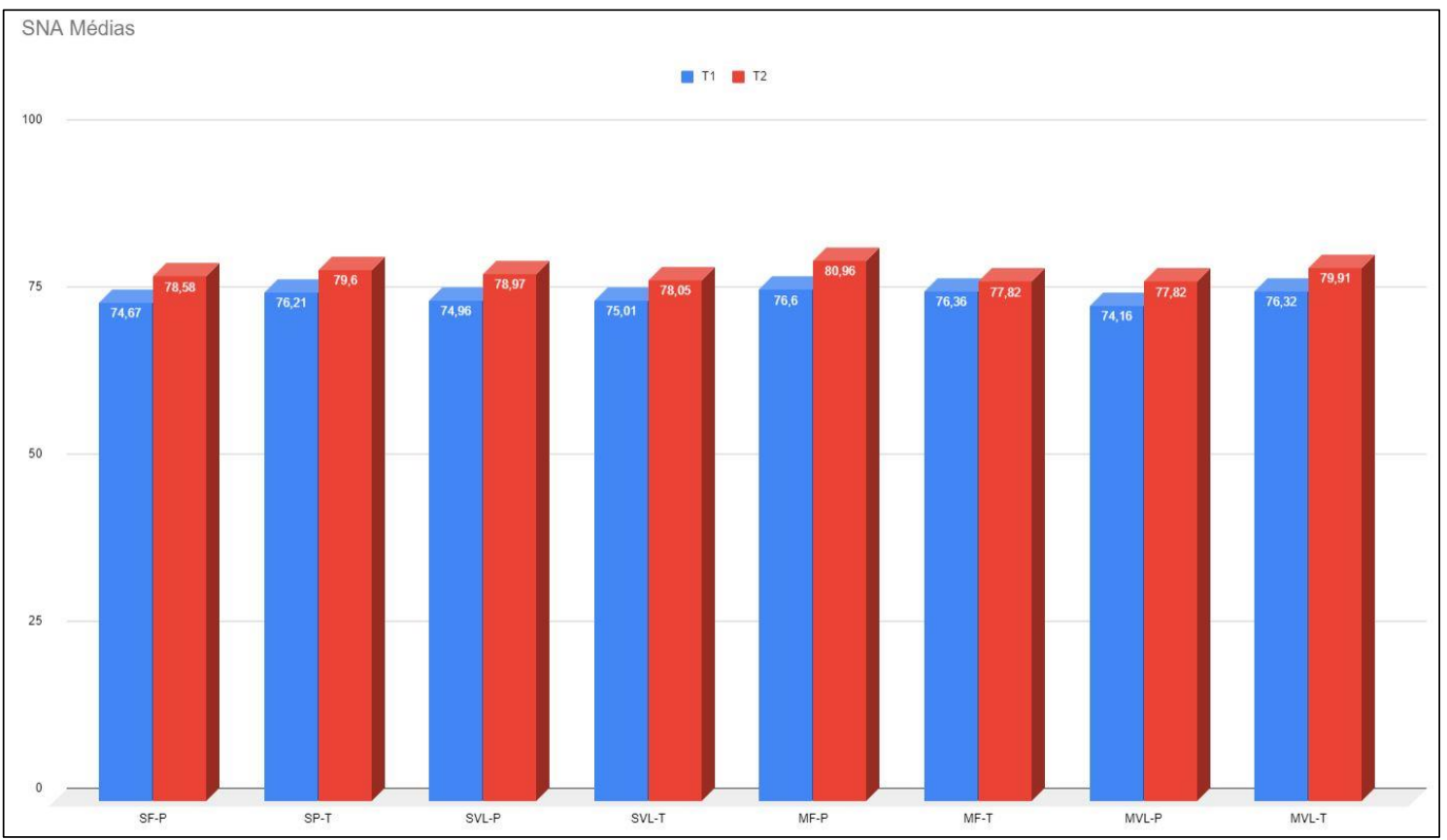

Fonte: Elaborada pelo autor.

Figura19 - Média dos Ângulos SNA e ANB dos grupos submetidos à protocolos distintos de palatoplastias com o fechamento do palato em um tempo, entre 9-12 meses (P) e entre 15-18 meses $(T)$

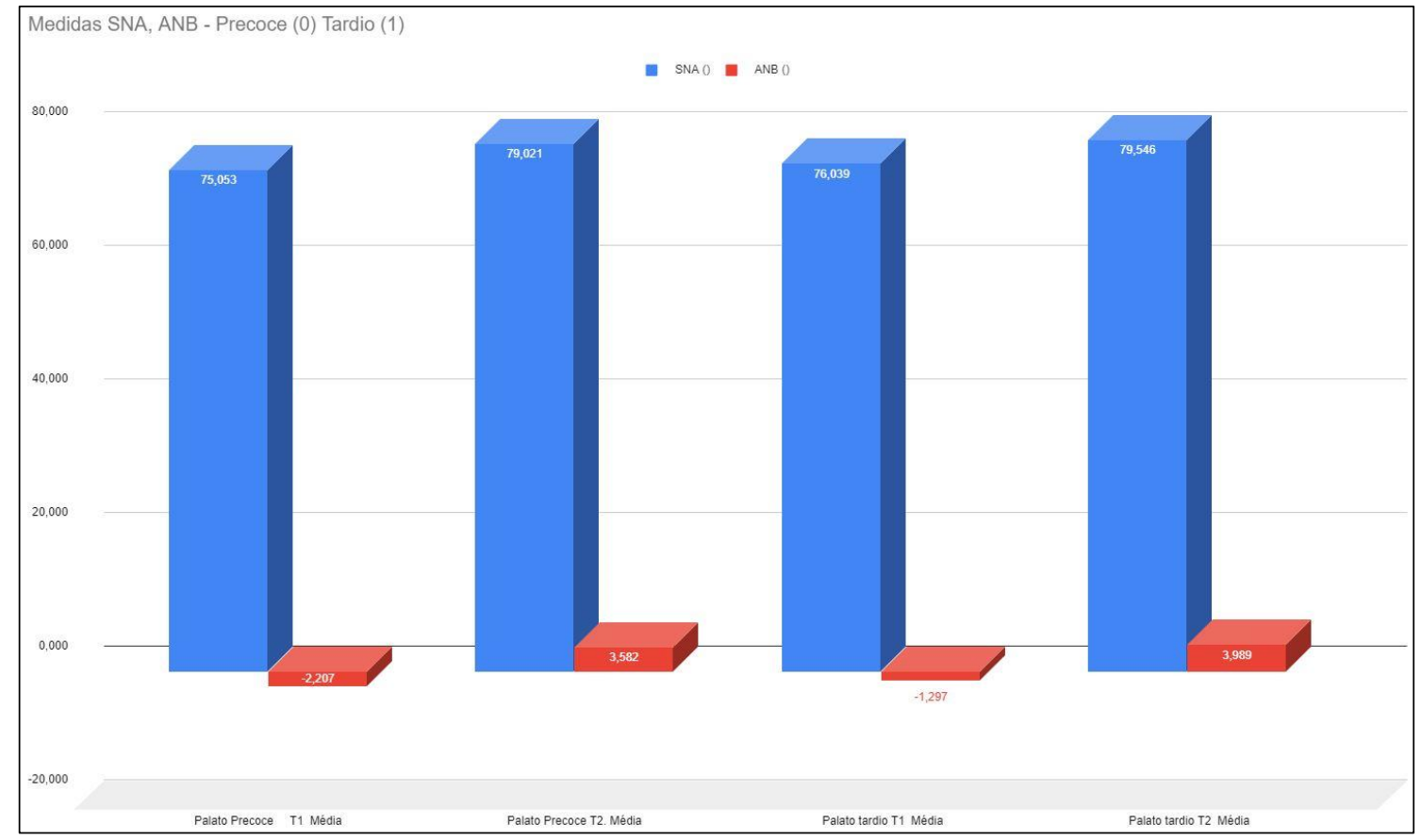

Fonte: Elaborada pelo autor. 
Figura 20 - Média dos Ângulos ANB dos grupos submetidos à protocolos distintos de queiloplastias e palatoplastias (SF; SVL; MF; MVL), com o fechamento do palato entre 9-12 meses $(P)$ e entre 15-18 meses $(T)$

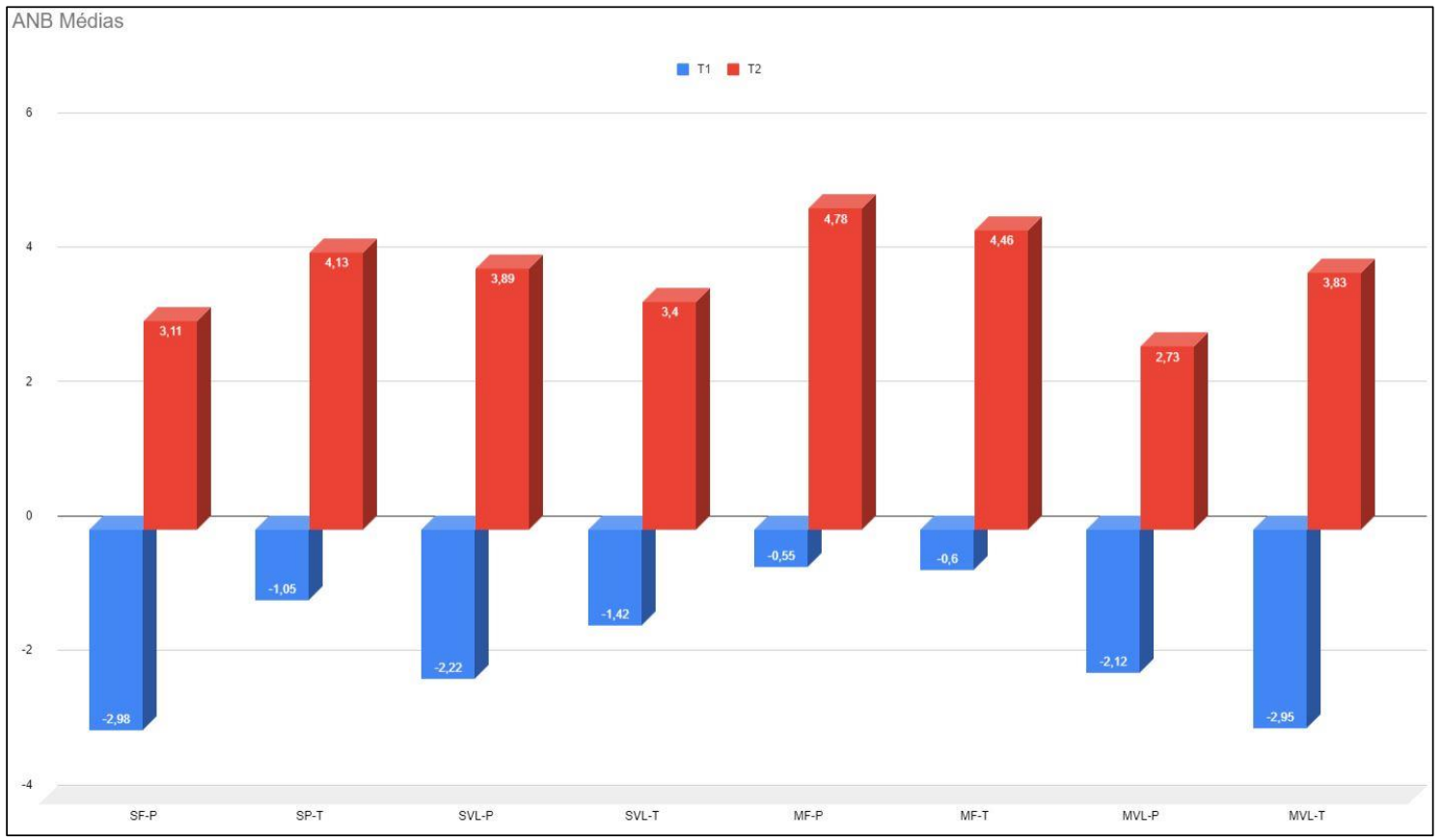

Fonte: Elaborada pelo autor.

Tabela 5 - Influência dos cirurgiões na posição sagital da maxila (SNA), mandíbula (SNB) e relação maxilomandibular (ANB). Comparação entre cirurgiões C1, C2, C3, C4 em T1 e T2

\begin{tabular}{cccccccccccccc}
\hline $\begin{array}{c}\text { T1 } \\
\text { Cirurgiões }\end{array}$ & C1 & C1 & & C2 & C2 & & C3 & C3 & & C4 & C4 & & \\
\hline Medidas & n & Média & DP & n & Média & DP & n & Média & DP & n & Média & DP & $\mathbf{p}$ \\
\hline SNA & 88 & 75,83 & 4,90 & 85 & 76,44 & 4,94 & 90 & 74,64 & 4,36 & 82 & 75,26 & 4,61 & 0,07 \\
SNB & 88 & 77,21 & 4,89 & 85 & 77,32 & 4,35 & 90 & 77,39 & 4,07 & 82 & 77,27 & 4,96 & 0.99 \\
ANB & 88 & $-1,38$ & 4,40 & 85 & $-0,87$ & 3,85 & 90 & $-2,75$ & 3,72 & 82 & $-2,00$ & 4,10 & $0,012^{*}$ \\
\hline
\end{tabular}

\begin{tabular}{ccccccccccccccc}
\hline $\begin{array}{c}\text { T2 } \\
\text { Cirurgiões }\end{array}$ & C1 & C1 & & C2 & C2 & & C3 & C3 & & C4 & C4 & & \\
\hline Medidas & $\mathbf{n}$ & Média & DP & $\mathbf{n}$ & Média & DP & $\mathbf{n}$ & Média & DP & n & Média & DP & $\mathbf{p}$ \\
\hline SNA & 88 & 79,54 & 5,15 & 85 & 79,90 & 4,59 & 90 & 79,07 & 4,50 & 82 & 78,67 & 4,91 & 0,36 \\
SNB & 88 & 75,94 & 4,16 & 85 & 75,20 & 3,62 & 90 & 75,60 & 4,26 & 82 & 75,26 & 4,11 & 0,60 \\
ANB & 88 & 3,59 & 4,09 & 85 & 4,70 & 3,29 & 90 & 3,48 & 3,11 & 82 & 3,41 & 3,44 & 0,05 \\
\hline
\end{tabular}

Nota: Entre os cirurgiões 2 e 3 apresentou diferença estatística $p=0,012^{*}$ apenas em T1 (na dentadura mista, antes do tratamento ortodôntico).

Fonte: Elaborada pelo autor. 
Figura 21 - Comparação do ângulo ANB entre cirurgiões C1, C2, C3, C4 em T1 e T2

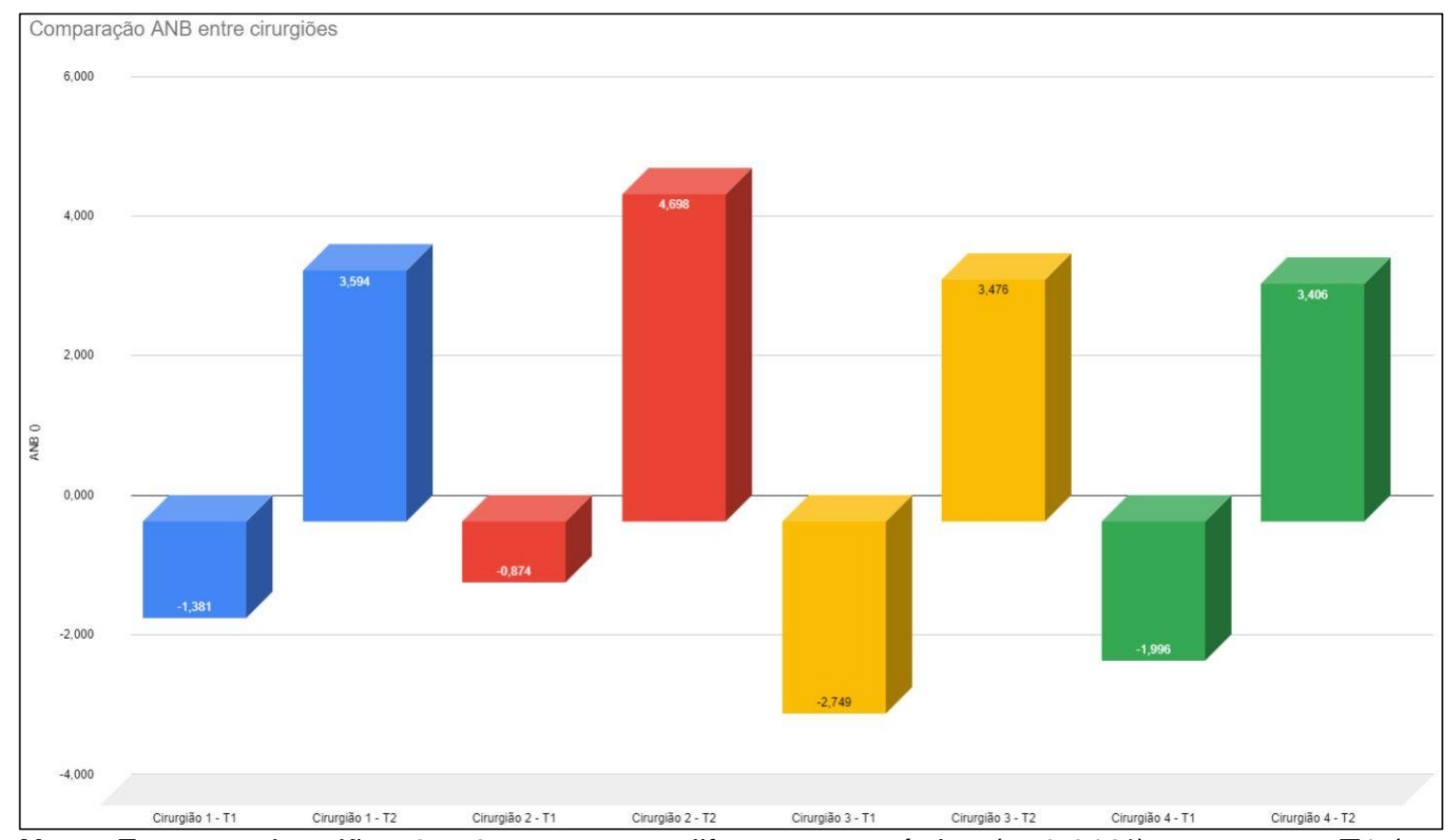

Nota: Entre os cirurgiões 2 e 3 apresentou diferença estatística $\left(p=0,012^{*}\right)$ apenas em T1 (na dentadura mista, antes do tratamento ortodôntico). Em T2, não houve diferença estatística entre nenhum dos cirurgiões com resultados do ANB positivos e próximos da normalidade de indivíduos sem fissura.

Fonte: Elaborada pelo autor.

Figura 22 - Comparação do ângulo SNA (relação sagital da maxila) entre cirurgiões C1, C2, C3, C4

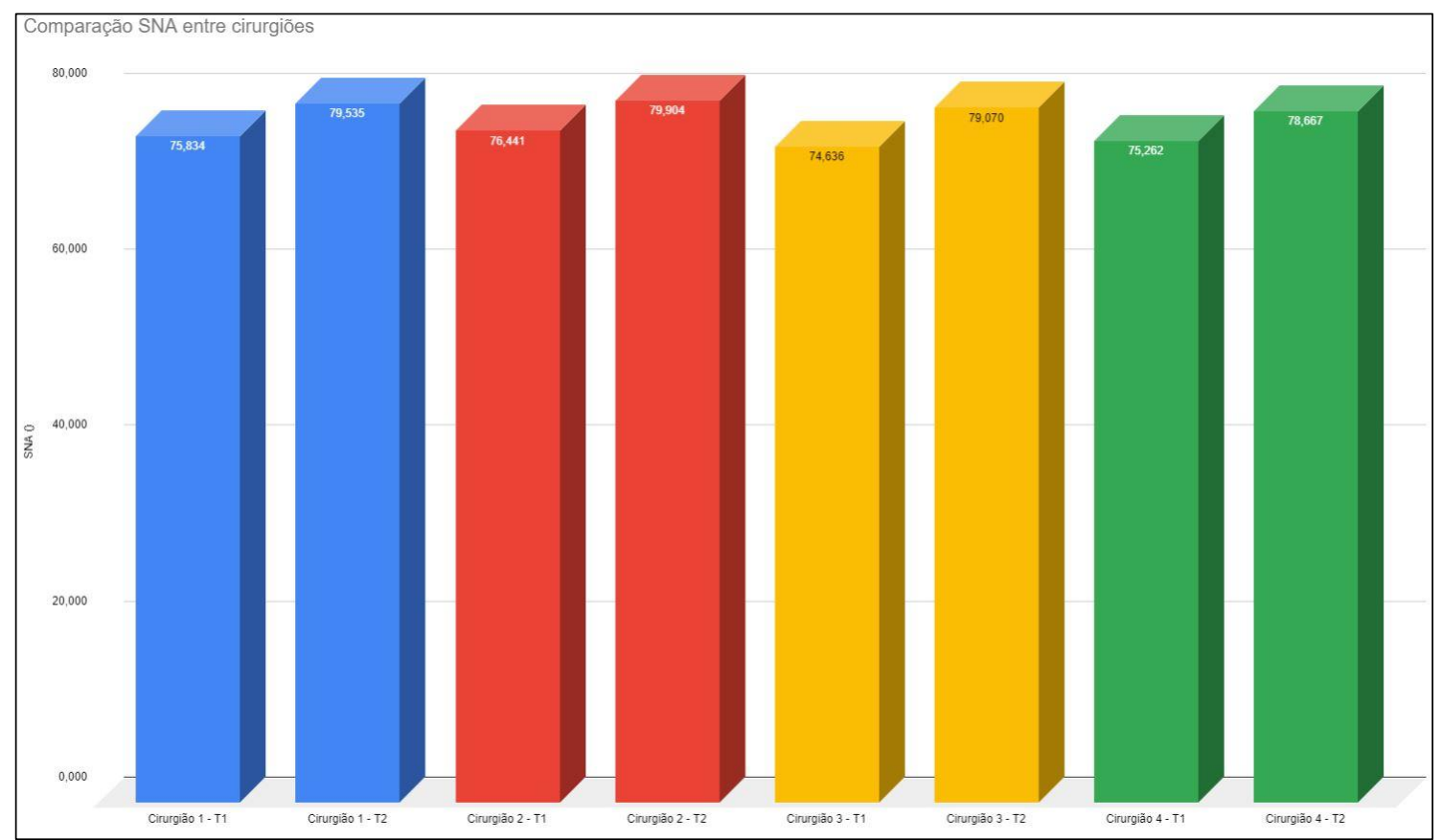

Nota: Mostrou que não houve diferença estatística na relação sagital da maxila (SNA) em T1 $(p=0,07)$ e T2 $(p=0,36)$.

Fonte: Elaborada pelo autor. 
Figura 23 - Comparação dos ângulos ANB e SNA entre cirurgiões (C1, C2, C3, C4) em T1 e T2

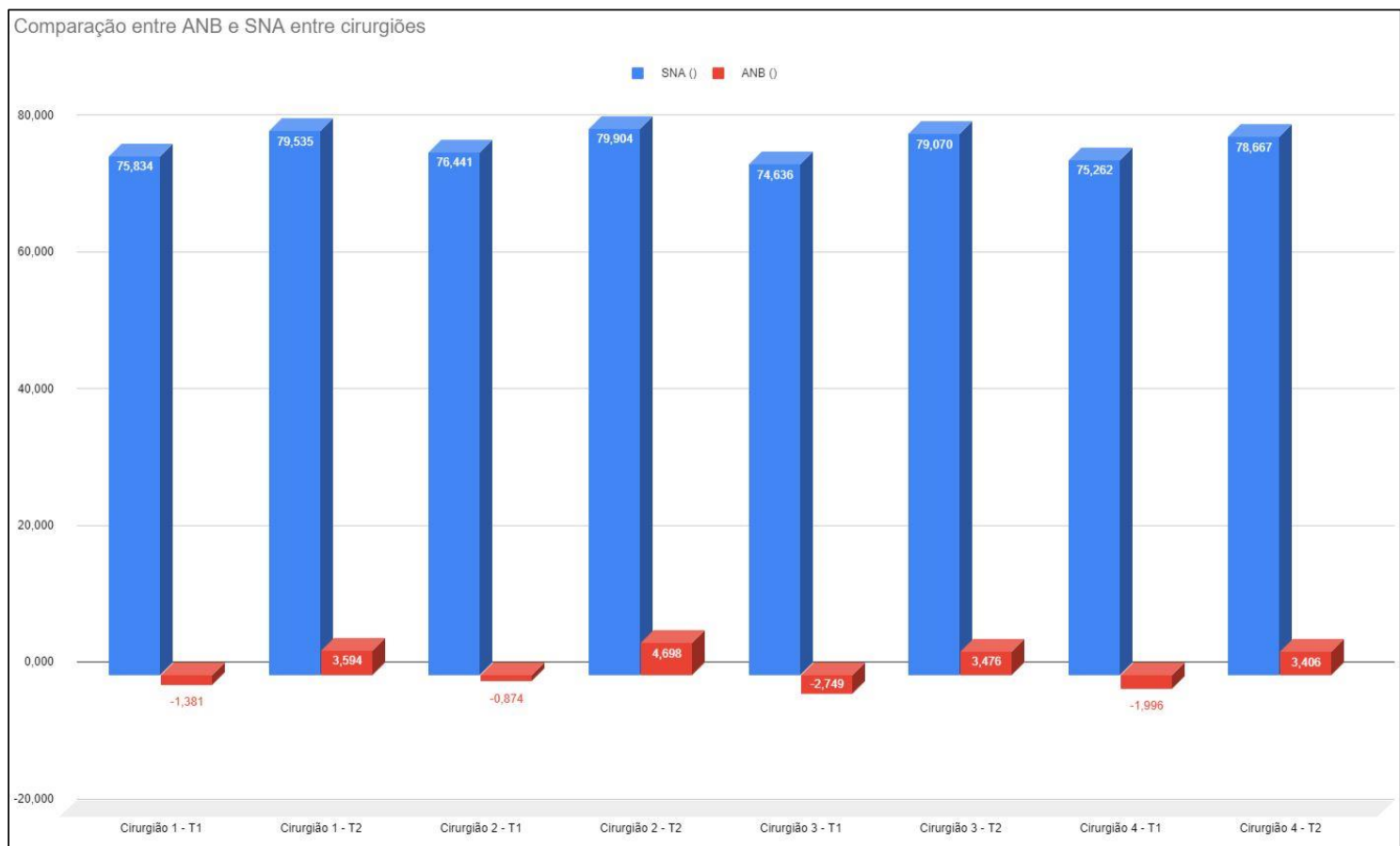

Nota: Os resultados do ANB em T1 (na dentadura mista, antes do tratamento ortodôntico) apresentou diferença estatística $\left(p=0,012^{*}\right)$ entre o cirurgião $2(A N B=-0,87)$ e cirurgião $3(A N B=-$ 2,75).

Fonte: Elaborada pelo autor. 

6 DISCUSSÃa 



\section{DISCUSSÃO}

De uma amostra de 466 pacientes de um estudo prévio, prospectivo e longitudinal foram selecionados 349 pacientes para o presente trabalho, que apresentaram duas telerradiografias laterais em duas fases: T1- na dentadura decídua/mista precoce (6 a 8 anos) sem nenhum tratamento ortodôntico nem enxerto ósseo alveolar (EOA) e T2- na dentadura permanente (a partir de 14 anos). Em T2 os pacientes já haviam sido submetidos ao tratamento ortodôntico/ ortopédico (expansão maxilar, máscara facial, aparelhos ortodônticos fixos) e enxerto ósseo alveolar. Para os casos que apresentaram um crescimento maxilar desfavorável, com prognostico ortodôntico cirúrgico foram selecionadas as telerradiografias antes da cirurgia ortognática.

No presente trabalho, avaliou-se longitudinalmente 0 crescimento craniofacial em indivíduos com FLPUC por meio de medidas angulares relacionadas à posição das bases maxilar (SNA), mandibular (SNB) e a relação entre a posição anteroposterior da maxila e mandíbula (ANB), relacionando com as técnicas de queiloplastia (Spina vs. Millard) aos 3-6 meses de idade e palatoplastia total em um tempo (Furlow vs. von Langenbeck), a idade no momento da cirurgia de palatoplastia ( 9 a 12 meses vs. 15 a 18 meses) e os quatro cirurgiões que realizaram as cirurgias.

O comportamento da maxila, mandíbula e a relação entre maxila e mandíbula de toda amostra na fase T1 (dentadura mista) e T2 (dentadura permanente) pode ser muito bem observado nas Figuras 1, 2, 3 e 4.

O gráfico de dispersão do angulo ANB (Figura 1) na amostra total de pacientes com FLPUC ( $\mathrm{n}=349$ ), operados do lábio pelas técnicas de Millard e Spina e do palato pelas técnicas de Von Langembeck e Furlow. Comparação da fase T1 (na dentadura mista) antes do tratamento ortodôntico com a fase T2 (dentadura permanente após tratamento ortodôntico/ortopédico + EOA). Em T1 o número de casos com ANB $<0$ eram muito maiores que em T2. Isso indica de alguma forma que o ANB em T2 tornou-se positivo pelo posicionamento mais anterior da maxila ou devido a rotação horária da mandíbula com as mecânicas ortopédicas, aumentando a discrepância entre as bases maxilar e mandibular (SNA - SNB = ANB). 
O gráfico da dispersão do ângulo SNA (Figura 2) mostra a comparação da fase T1 antes do tratamento ortodôntico com a fase T2 na dentadura permanente após tratamento ortodôntico/ortopédico + EOA). Em T1 o número de casos com SNA <80응 era a maioria. Em T2 o SNA $>80^{\circ}$ aumentou consideravelmente, enquanto o gráfico da dispersão do ângulo SNB (Figura 3) evidencia que na fase T1 o número de casos com SNB $<80^{\circ}$ era a maioria, com um número médio de SNB entre 80 a 85․ Em T2 o SNB $>80^{\circ}$ reduziu consideravelmente. Isso indica que a mandíbula está rotando no sentido horário, para baixo e para trás.

O estudo cefalométrico do Americleft envolvendo quatro centros de referência, avaliou pacientes com FLUC com idade variando de 6 a 12 anos (média de 8 anos e 8 meses) e encontrou valores médios de SNA entre 76,3-a 79,8-; média de SNB variando de $73,9^{\circ}-$ a $74,5^{\circ}$; e o ângulo ANB médio dos quatro centros foi de 2,$4 ; 3,34 ; 3,37$ e 5,42 , todos com valores positivos mostrando uma relação maxilomandibular favorável (DASKALOGIANNAKIS et al., 2011). Neste mesmo estudo, uma correlação bastante interessante também foi realizada comparando o comportamento do ângulo ANB com o índice de Goslon mostrando que quanto menor o índice Goslon, maior o ângulo ANB e melhor relação maxilomandibular.

Kappen et al. (2017) do centro de Utrecht, avaliaram o crescimento longitudinal por meio de análise cefalométrica em pacientes adultos com FLPUC submetidos à palatoplastias em dois estágios e encontrou valores médios de $\mathrm{SNA}=74,9 ; \mathrm{SNB}=75,8$ e $\mathrm{ANB}=-0,9$. Quando comparados os valores do SNA e ANB com os trabalhos longitudinais pode-se constatar que são próximos ao da maioria dos centros do Eurocleft, tanto de centros que operaram o palato em um único estágio (Centros B, E, F) e centros que operou em 2 estágios (Eurocleft Centro A e Niemegen). Os ângulos SNA variaram de 72,9 a 76,8, enquanto o ANB variou de -1 a -2,4.

No presente estudo com palatoplastia num único estagio, observou-se uma variação do SNA entre $75,3^{\circ}$ a $79,6^{\circ}$ na fase T1 (dentadura mista sem tratamento ortodôntico prévio) e na fase T2 (dentadura permanente, observou-se variação de $75^{\circ}$ a $79,9^{\circ}$.

Meazzini et al. (2008) citaram a metodologia para classificar e agrupar de acordo com os valores médios do ângulo ANB: $\left(-7^{\circ} \mathrm{a}-1^{\circ}\right) ;\left(-1^{\circ} \mathrm{a}+2^{\circ}\right)$; ANB $>+2^{\circ}$, possibilitando separar os casos com discrepância esquelética de classe III, com prognostico ortodôntico-cirúrgico. 
Analisando a distribuição do ângulo ANB Figura 8 do presente estudo ( $n=349)$, observou-se que em T1 antes de qualquer manejo ortodôntico/ortopédico, $55,3 \%$ dos casos apresentaram de ANB variando de $\left(-7^{\circ} \mathrm{a}-1^{\circ}\right)$ compatível com Classe III esquelética, $27,2 \%$ com o ANB entre $\left(-1^{\circ} \mathrm{o}+2^{\circ}\right)$ enquanto $17,5 \%$ apresentaram ANB $>+2^{\circ}$ (normal para a fase). Em T2, na dentadura permanente após o manejo ortodôntico/ortopédico + EOA e alguns casos com tratamento ortodôntico compensatório, esse cenário modificou-se, aumentando de $17,5 \%$ para $70,8 \%$ os casos com ANB $>+2^{\circ}$, reduzindo de $55,3 \%$ para $9,7 \%$ o percentual de ANB entre $\left(-7^{\circ}\right.$ $\left.a-1^{\circ}\right)$ e $19,5 \%$ de casos com ANB entre $\left(-1^{\circ} a+2^{\circ}\right)$ (Figura 8$)$.

A influência da queiloplastia (Spina e Millard) e da palatoplastia (von Langenbeck e Furlow) no comportamento sagital da maxila, mandíbula e na relação maxilomandibular pode ser observado na Tabela 1 e nos Gráficos apresentados nas Figuras 9, 10, 11 e 12.

Dos 349 casos com FLPUC, 185 foram operados pela técnica de Millard e 164 pela técnica de Millard. Na palatoplastia, 175 foram operados pela técnica de Von Langenbeck e 174 pela técnica de Furlow. A técnica de Millard ou Spina não influenciaram nem na posição sagital da maxila (SNA), da mandíbula (SNB) assim como do ângulo ANB (relação maxilomandibular, nem na fase T1 nem em T2 (Tabela 2; Figuras 10 e 12).

A palatoplastia (VL ou Furlow) não influenciou na posição maxilar (SNA) e mandibular (SNB), nas fases T1 e T2. No entanto, apresentou diferença estatística no ângulo ANB na fase $T 1(p=0,02)$ antes do tratamento ortodôntico e ortopédico entre as técnicas de Furlow $(A N B=-1,22)$ e a técnica de Von Langenbeck (ANB=-2,26). Isto indica que a técnica de $\mathrm{VL}$ influenciou mais negativamente na relação maxilomandibular (ANB) em T1. Na fase T2, na dentadura permanente, o ANB foi similar nas duas técnicas de palatoplastia (F e VL) (Tabela 2; Figuras 11 e 13).

Quando avaliou-se a diferença entre o comportamento sagital da maxila, mandíbula e a relação maxilomandibular entre os quatro subgrupos operados pela técnica de: Spina-Furlow (S-F); Spina-Von Langenbeck (S-VL); Millard-Furlow (M-F); Millard-Von Langenbeck (VL), observou-se que tanto em T1 como em T2, não houve diferença estatística nos valores de SNA e SNB (Tabela 2; Figura 15). Os valores médios do ângulo SNA apresentaram reduzidos em todos os subgrupos em T1, antes de qualquer manejo ortodôntico/ortopédico. Já na dentadura permanente (T2), após o 
manejo ortodôntico/ortopédico associado ao crescimento, houve incrementos de crescimento e a média do ângulo SNA aumentou consideravelmente, mas sem diferenças entre os subgrupos avaliados (S-F); (S-VL); (M-F); (M-VL). Os valores médios do ângulo SNB diminuíram em todos os subgrupos de T1 para T2, embora sem diferença estatística. Essa redução não implica em falta de crescimento mandibular, mas sim uma rotação horária da mandíbula, resultante do manejo ortodôntico, conforme relatado na literatura.

A relação maxilo-mandibular (ANB) em T1 apresentou diferença estatística entre as técnicas M-VL $(-2,58)$ e M-F $(-0,58)$ (Tabela 2; Figura 14). Na dentadura mista apresentou-se uma discrepância negativa maior no grupo $\mathrm{M}-\mathrm{VL}$ em relação ao grupo $\mathrm{M}-\mathrm{F}$, mas após o tratamento ortodôntico/ortopédico, em T2, tanto o grupo M-VL como o grupo M-F, assim como os grupos SVL e SF tiveram a relação sagital corrigida e apresentaram a média dos ângulos ANB positivo e acima de 3o (próximo de um indivíduo sem FLP) e sem diferença estatística. $O$ aumento do ângulo ANB resulta em função do manejo ortodôntico alterando a posição sagital da maxila e principalmente da rotação da mandíbula.

Meazzini et al. (2008) avaliaram a amostra de Milão e Oslo utilizando uma distribuição do grau de protrusão maxilar (SNA) e a relação sagital maxilomandibular (ANB). Para facilitar a análise, distribuiu as variáveis cefalométricas sagitais em quatro

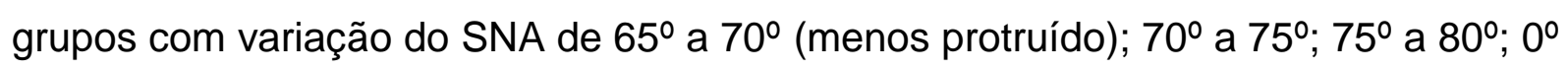
a 85ํㅡ (a mais protruída); e a variação do ângulo ANB entre ( $4^{\circ}$ a $2^{\circ} ; 2^{\circ}$ a- $1^{\circ}$; $-1^{\circ}$ a $-4^{\circ}$;

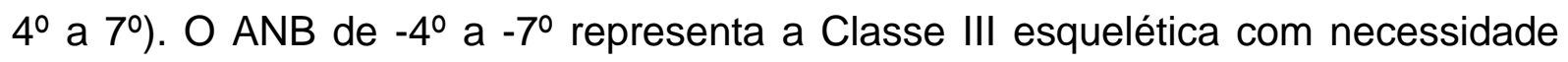
ortodôntico cirúrgica.

Baseado nessa classificação de Meazzini et al. (2008), verificou-se a distribuição dos ângulos ANB do presente estudo de acordo com os diferentes protocolos cirúrgicos (MF; MVL; SF; SVL), em T1 e T2. Na Figura 16 pode-se visualizar quatro gráficos dos quatro subgrupos de protocolos cirúrgicos para cirurgias primárias de lábio e palato.

$\mathrm{Na}$ amostra total de 349 pacientes com FLPUC (Figura 4) observou-se na fase T2 (dentadura permanente) um total de 9,73\% da amostra com ANB $<-1$ o e apenas $2 \%$ com ANB $<-4^{\circ}$. O ANB $>2^{\circ}$ foi encontrado em $70,7 \%$ da amostra e $19,5 \%$ apresentou ANB de $-1^{\circ}-\mathrm{a}+2^{\circ}$. 
Analisando individualmente cada protocolo cirúrgico apresentado na Figura 16, o grupo M-F ( $n=85)$ apresentou a menor casuística de ANB $<-1^{\circ}$ que foi de 3,5\% da amostra em T2. Observou-se ainda que $81 \%$ da amostra apresentou ANB >+2ㅇ; e 15,3\% um ANB de -1 으 a $+2^{2}$ ․ Em T1 41\% apresentava ANB <-1ำ e em T2 reduziu drasticamente para 3,5\% o ANB <-1ํapós o manejo ortodôntico.

O Grupo M-VL $(n=100)$ apresentou em T2, 65\% de ANB >+2ํ; $23 \%$ de ANB de $-1^{\circ} \mathrm{a}+2^{\circ}$ e $12 \%$ de ANB $<-1^{\circ}$. Em T1 $64 \%$ tina ANB $<-1^{\circ}-$.

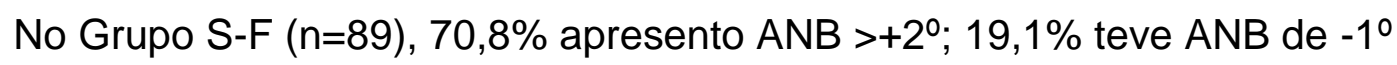
a +2ㅇ; e 10,1\% um ANB <-1ㅇ. Em T1, apresentava 55,05\% de ANB <-1ํ-.

No Grupo S-VL ( $\mathrm{n}=75), 66,7 \%$ apresentou ANB >+2ำ em T2; $20 \%$ teve 0 ANB entre -1ํ- a +2ำ-; e 13,3\% apresentou ANB <-1ํ-. Neste grupo $60 \%$ apresentava em T1 um ANB <-1ㅇ-.

Esses dados apontam que o percentual de casos com necessidade ortodôntico-cirúrgico varia de 10 a 13\% em três grupos (M-VL, S-F, S-VL) e no Grupo M-F apresentou um percentual reduzido de 3,5\%. Na amostra total o percentual de casos com provável necessidade cirúrgica girou em torno de $10 \%$ da amostra. Seria muito interessante correlacionar os índices de Goslon que classificam a severidade da má-oclusão com a severidade da relação maxilomandibular sagital por meio de medidas cefalométricas (ANB).

Os gráficos da Figura 17 ilustram o percentual de distribuição do ângulo SNA que representa o grau de protrusão ou retrusão da maxila no sentido sagital nos 4 subgrupos de protocolos cirúrgicos para cirurgias primárias de lábio e palato.

$\mathrm{Na}$ amostra total ( $\mathrm{n}=349), 17,5 \%$ da amostra apresentou em T2 o SNA $<75^{\circ}$ da Figura 9. O SNA menor que 75-. indica deficiência sagital da maxila. Desta forma os pacientes com FLPU apresentam em sua grande maioria déficit anteroposterior da maxila e o SNA entre 75 a 80 está dentro da normalidade. $82,5 \%$ da amostra total apresentou SNA >76우 ; e 41,25\% com SNA > $80^{\circ}-$.

No grupo M-F, 14,1\% da amostra apresentou em T2 um ângulo SNA <75; $34,1 \%$ de SNA entre $76-80^{\circ}-; 51,8 \%$ de SNA $>80^{\circ}$.

No grupo M-VL, observou-se $16,5 \%$ de casos com SNA $<75^{\circ} ; 45 \%$ de SNA entre 76 a $80^{\circ}$ e $39 \%$ de SNA $>80^{\circ}$. 
No grupo S-F, 16,85\% apresentou SNA $<75^{\circ} ; 40,5 \%$ com SNA entre 76 a $80^{\circ} ; 43 \%$ de casos com SNA $>80^{\circ}$.

No Grupo S-VL observou-se $24 \%$ de SNA $<75^{\circ} ; 45,3 \%$ de SNA entre 76 a $80^{\circ}-; 30,7 \%$ de $S N A>80^{\circ}$.

Os dados indicam que de $14 \%$ a $24 \%$ dos indivíduos que receberam diferentes protocolos de cirurgias primárias apresentam deficiência sagital da maxila, com o ângulo SNA $<75^{\circ}$ podendo necessitar de correção cirúrgica para ajustar a discrepância esquelética do padrão III.

A Tabela 3 e as Figuras 18, 19 e 20 ilustram o comportamento sagital da maxila, mandíbula e a relação maxilomandibular em pacientes FLPUC submetidos à palatoplastia em um tempo em idade precoce (9-12 meses) e tardio (15-18 meses) nas fases T1 (dentadura decídua e mista) e T2 (permanente).

A média dos ângulos SNA e SNB dos grupos submetidos à protocolos distintos de queiloplastias e palatoplastias (SF; SVL; MF; MVL), com o fechamento do palato entre 9-12 meses (P) e entre 15-18 meses $(T)$ não apresentou diferença estatística tanto na fase da dentadura mista como da dentadura permanente. Apenas a relação maxilomandibular (ANB) apresentou diferença estatística na fase T1 (dentadura mista), entre o grupo operado mais precocemente e grupo tardio, indicando uma discrepância mais negativa no grupo operado mais precocemente $(A N B=-2,2)$ do que o grupo operado mais tardiamente $(A N B=-1,3)$. Valor de $p=0,03^{*}$. $\mathrm{Na}$ dentadura permanente essa diferença do ANB entre o grupo operado precoce e tardiamente foi corrigida após o manejo ortodôntico e ortopédico. A média dos dois grupos passaram de ANB negativo para um ANB acima de 3,5, de indivíduos sem fissura. $\mathrm{O}$ aumento do ANB se deve em boa parte à rotação mandibular para baixo $\mathrm{e}$ para trás, resultante do processo de reabilitação e do desenvolvimento longitudinal.

Vários trabalhos na literatura citam a influência da variável "habilidade do cirurgião nos resultados do crescimento maxilar e facial.

O comportamento sagital da maxila (SNA), mandíbula (SNB) e relação maxilomandibular (ANB), de indivíduos com FLPUC apresenta-se alterado quando comparados à indivíduos sem a FLP (SEMB, 1991).

No presente trabalho, verificou-se que entre os quatro cirurgiões que operaram a amostra (C1, C2, C3, C4) o cirurgião 2 e 3 apresentaram diferença 
estatística no ângulo ANB $\left(p=0,012^{*}\right)$ na fase $T 1$ (na dentadura mista, antes do tratamento ortodôntico). $O$ cirurgião 2 apresentou melhores resultados, com média de $\mathrm{ANB}=-0,87$ (menos discrepante); enquanto o cirurgião 3, teve a média do $\mathrm{ANB}=-2,75$ (+ discrepante). Entre os cirurgiões 1, 2 e 4 não houve diferença (Tabela 5; Figura 21).

$\mathrm{Na}$ fase T2, na dentadura permanente, não houve diferença estatística nos resultados da relação maxilomandibular dos quatro cirurgiões. A discrepância negativa existente no ANB na dentadura mista foi corrigida com manejos ortodônticos durante os protocolos de reabilitação, apresentando aumento do ANB de -0,87 para $+4,7$ (Cirurgião 2) e de -2,75 para +3,48 (Cirurgião 3) (Tabela 5; Figuras 21 e 23).

Na comparação do ângulo SNA (relação sagital da maxila) entre os cirurgiões $\mathrm{C} 1, \mathrm{C} 2, \mathrm{C} 3, \mathrm{C} 4$, não houve diferença estatística na relação sagital da maxila entre os cirurgiões, nas duas fases T1 e T2 (Figura 22). 

7 ロロNCLUSÃロ 



\section{CONCLUSÃO}

Com base nos resultados da avaliação cefalométrica longitudinal de pacientes com FLPUC, foi possível concluir que:

- na fase T1 (antes de qualquer manejo ortodôntico) o número de casos com ANB $<0$ eram muito maiores que em T2 (dentadura permanente). Em T2 após manejo ortodôntico-ortopédico, o ANB $>0$ aumentou pelo posicionamento mais anterior da maxila e devido a rotação horária da mandíbula; o SNA $>80^{\circ}$ aumentou consideravelmente, enquanto o SNB $>80^{\circ}$ reduziu consideravelmente, com tendência de rotação mandibular no sentido horário, para baixo e para trás;

- da amostra total ( $n=349$ ), observou-se na fase T2 (dentadura permanente, após acompanhamento ortodôntico-ortopédico + EOA), um percentual de 9,73\% com ângulo ANB de (-7ํ- a -1ํㅜ), com provável prognóstico ortodôntico-cirúrgico e $70 \%$ dos casos com ANB >2º, compatível com os indivíduos normais sem fissura;

- a técnica de Queiloplastia (Millard ou Spina) não influenciaram nem na posição sagital da maxila (SNA), da mandíbula (SNB) e na relação maxilomandibular (ANB) na fase T1 e T2;

- a técnica de palatoplastia (VL ou Furlow) não influenciaram na posição maxilar (SNA) e mandibular (SNB), nas fases T1 e T2. No entanto, a técnica de VL influenciou mais negativamente no ANB do que a técnica de $F$, na fase T1. Na fase T2, o ANB foi similar nas técnicas VL e $F$.

- o comportamento sagital da maxila (SNA), mandíbula (SNB) não apresentaram diferença estatística entre os subgrupos operados pela técnica de: (S-F); (S-VL); (M-F); (VL), tanto em T1 como em T2. Somente a técnica $M-V L(-2,58)$ mostrou-se menos favorável que M-F $(-0,58)$ em T1, enquanto em T2, após o tratamento ortodôntico/ortopédico, todos os grupos (M-VL; M-F, S-VL e S-F) tiveram a relação sagital corrigida e apresentaram a média dos ângulos ANB >+3ํㅡ (próximo de um indivíduo sem FLP) e sem diferença estatística; 
- o fechamento do palato em um único estágio, em idade precoce (9-12 meses) e tardio (15-18 meses) não apresentou diferença estatística no comportamento do SNA e SNB operados por diferentes técnicas (SF; SVL; MF; MVL), nas fases T1 e T2. Apenas na fase T1 (dentadura mista), o ANB apresentou uma discrepância mais negativa no grupo operado mais precocemente $(A N B=-2,2)$ do que o grupo operado mais tardiamente $(A N B=-1,3)$. Valor de $p=0,03^{*}$. Na fase T2 essa diferença do ANB entre o grupo operado precoce e tardiamente foi corrigida após o manejo ortodôntico e ortopédico. A média dos dois grupos passaram de ANB negativo para um ANB acima de 3,5, compatível à de indivíduos sem fissura;

- não houve diferença estatística na relação sagital da maxila (SNA) entre os quatro cirurgiões, nas fases T1 e T2. Houve diferença estatisticamente significante na relação maxilomandibular (ANB) na fase $T 1$ entre os cirurgiões 2 e 3 (mais favorável). Em T2, todos os quatro cirurgiões apresentaram resultados satisfatórios, com ANB positivos e próximos dos valores médios de indivíduos sem fissura. 
REFERÊNCIAS 



\section{REFERÊNCIAS}

ANGER, J. Prof. Perseu Castro de Lemos e Prof. Victor Spina: a história da plástica em Z na queiloplastia para a correção das fissuras lábio palatinas

unilaterais. Revista Brasileira de Cirurgia Plástica, v. 20, n. 4, p. 245-247, 2005.

BICHARA, L. M. et al. Impact of primary palatoplasty on the maxillomandibular sagittal relationship in patients with unilateral cleft lip and palate: a systematic review and meta-analysis. Int J Oral Maxillofac Surg, v. 44, n. 1, p. 50-56, 2015.

BROADBENT, B. H. A new x-ray technique and its application to orthodontia. Angle Orthod, v. 1, n. 2, p. 45-66, 1931.

CAPELOZZA FILHO, L.; NORMANDO, A. D.; SILVA FILHO, O. G. Isolated influences of lip and palate surgery on facial growth: comparison of operated and unoperated male adults with UCLP. Cleft Palate-Craniofac J, v. 33, n. 1, p. 51-56, 1996.

CAVASSAN, A. O.; SILVA FILHO O. G. Abordagem ortodôntica. In: TRINDADE, I. E. K.; SILVA FILHO, O. G. Fissuras labiopalatinas: uma abordagem interdisciplinar.

São Paulo: Santos; 2007. cap. 12, p. 213-236.

CYMROT, M. et al. Prevalência dos tipos de fissura em pacientes com fissuras labiopalatinas atendidos em um Hospital Pediátrico do Nordeste brasileiro. Rev Bras Cir Plást, v. 25, n. 4, p. 648-651, 2010.

DASKALOGIANNAKIS, J. et al. The americleft study: an inter-center study of treatment outcomes for patients with unilateral cleft lip and palate part 3. Analysis of craniofacial form. Cleft Palate Craniofac J, v. 48, n. 3, p. 252-258, 2011.

DOWNS, W. B. Analysis of the dentofacial profile. Angle Orthod, v. 26, n. 4, p. 191 212, 1956.

FREITAS, J.A.S. et al. Rehabilitative treatment of cleft lip and palate: experience of the Hospital for Rehabilitation of Craniofacial Anomalies/USP (HRAC/USP) - Part 1: overall aspects. J Appl Oral Sci, Bauru, v. 20, n. 1, p. 9-15, 2012 a.

FREITAS, J. A. S. et al. Rehabilitative treatment of cleft lip and palate: experience of the Hospital for Rehabilitation of Craniofacial Anomalies-USP (HRAC-USP) - Part 2: Pediatric Dentistry and Orthodontics. J Appl Oral Sci, v. 20, n. 2, p. 268-281, $2012 b$.

FUDALEJ, P. et al. Dental arch relationship in children with complete unilateral cleft lip and palate following one-stage and three-stage surgical protocols. Clin Oral Investig, v. 15, n. 4, p. 503-510, 2011.

FURLOW, L. T Jr. Cleft palate repair by double opposing Z-plasty. Plast Reconstr Surg, v. 78, n. 6, p. 724-738, 1986. 
FURLOW, L. T. Cleft palate repair: preliminary report on lengthening and muscle transposition by Z-plasty. In: THE ANNUAL MEETING OF THE SOUTHEASTERN SOCIETY OF PLASTIC AND RECONSTRUCTIVE SURGEONS. Boca Raton, 16 May 1978.

GARIB, D. G. et al. Fissuras labiopalatinas: a ortodontia no processo reabilitador. Pro-Odonto Ortodontia, Bauru, v. 3, p. 115-176, 2010.

GOPINATH, V. K. et al. Facial profile and maxillary arch dimensions in unilateral cleft lip and palate children in the mixed dentition stage. Eur J Dent, v. 11, n. 1, p. 76-82, 2017.

HAQUE, S.; ALAM, M. K.; KHAMIS, M. F. The effect of various factors on the dental arch relationship in non-syndromic unilateral cleft lip and palate children assessed by new approach: a retrospective study. BMC Pediatrics, v. 17, n. 1, p. 119-126, 2017.

HELIÖVAARA, A. et al. Scandcleft randomised trials of primary surgery for unilateral cleft lip and palate: 6 . Dental arch relationships in 5 year-olds. J Plast Surg Hand Surg, v. 51, n. 1, p. 52-57, 2017.

HOFRATH, H. Die bedeutung der röntgenfern-und abstandsaufnahme für die diagnostik der kieferanomalien. Fortschr Orthodont, v. 1, n. 2, p. 232-258, Apr./July. 1931.

HOLDAWAY, R. A. Changes in relationship of points $A$ and $B$ during orthodontic treatment. Am J Orthod, v. 42, n. 3, p. 176-193, 1956.

KAPPEN, I. F. P. M. et al. Long-term mid-facial growth of patients with a unilateral complete cleft of lip, alveolus and palate treated by two-stage palatoplasty:

cephalometric analysis. Clin Oral Invest, v. 21, n. 5, p. 1801-1810, 2017.

LEOW, A. M.; LO, L. J. Palatoplasty: evolution and controversies. Chang Gung Med J, v. 31, n. 4, p. 335-45, 2008.

LIAO, Y. F.; MARS, M. Long-term effects of palate repair on craniofacial morphology in patients with unilateral cleft lip and palate. Cleft Palate Craniofac J, v. 42, n. 6, p. 594-600, 2005.

MARQUES, R.M.F.; LOPES, L.D.; KHOUTY, R. B. F. Embriologia. In: ALTMANN, E. B. C. Fissuras labiopalatinas. 4. ed. Carapicuíba: Pró-Fono, 1997. cap. 12, p. 3-24

MARS, M.; HOUSTON, W. J. B. A preliminary study of facial growth and morphology in unoperated male unilateral cleft lip and palate subjects over 13 years of age. Cleft Palate J, v. 27, n. 1, p. 7-10, 1990.

MCNAMARA, J. A. A method of cephalometric evaluation. Am J Orthod, v. 86, n. 6 , p. 449-469, 1984.

MEAZZINI, M. C. et al. A cephalometric intercenter comparison of patients with unilateral cleft lip and palate: analysis at 5 and 10 years of age and long term. Cleft Palate Craniofac J, v. 45, n 6, p. 654-660, 2008. 
MIACHON, M. D.; LEME, P. L. S. Surgical treatment of cleft lip. Rev Col Bras Cir, v. 41, n. 3, p. 208-214, 2014.

MOREIRA, I. et al. Soft-tissue profile growth in patients with repaired complete unilateral cleft lip and palate: A cephalometric comparison with normal controls at ages 7, 11, and 18 years. Am J Orthod Dentofacial Orthop, v. 145, n. 3, p. 341358, 2014.

MURRAY, J. C. Gene/environment causes of cleft lip and/or palate. Clin Genet, Vancouver, v. 61, n. 4, p. 249-255, 2002.

OZAWA, T. O. Avaliação dos efeitos da queiloplastia e palatoplastia primária sobre o crescimento dos arcos dentários de crianças com fissura transforame incisivo unilateral aos 5 6 anos de idade. 2001. 205 p. Tese (Doutorado em Ortodontia) - Faculdade de Odontologia de Araraquara, Universidade Estadual Paulista, Araraquara, 2001.

RICKETTS, R. M. Esthetics, environment, and the law of lip relation. Am J Orthod, v. 54, p. 272-289, 1968.

RIEDEL, R. A. An analysis of dentofacial relationships. Amer J Orthod, v. 43, n. 2, p. 103-119, 1957.

SAKODA, K. L. et al. 3D analysis of effects of primary surgeries in cleft lip/palate children during the first two years of life. Braz Oral Res, São Paulo, v. 31, e 46, 2017.

SEMB, G. A study of facial growth in patients with unilateral cleft lip and palate treated by the Oslo CLP team. Cleft Palate Craniofac J, v. 28, n. 1, p. 1-21, 1991.

STEINER, C. C. Cephalometrics for you and me. Amer J Orthod, v. 39, n. 10, p. $729-755,1953$.

TRINDADE, I. E. K.; SILVA FILHO, O. G. Fissuras labiopalatinas: uma abordagem interdisciplinar. São Paulo: Santos, 2007. 337 p.

TWEED, $\mathrm{C} . \mathrm{H}$. The diagnostic facial triangle in the control of treatment objectives. Amer J Orthod, v. 55, n. 6, p. 651-667, 1969.

VASCONCELOS, M. H. F. Avaliação de um programa de traçado cefalométrico. 2000. 224p. Tese (Doutorado em Ortodontia) - Faculdade de Odontologia de Bauru, Universidade de São Paulo, Bauru, 2000.

WILLIAMS, W. N. et al. Prospective clinical trial comparing outcome measures between Furlow and von Langenbeck palatoplasties for UCLP. Ann Plast Surg, v. 66, n. 2 , p. $154-163,2011$. 